\title{
Development of a Spray-Based Phenomenological Soot Model for Diesel Engine Applications
}

\author{
Alessio Dulbecco and Gregory Font \\ IFP Energies Nouvelles, Institut Carnot IFPEN TE
}

\begin{abstract}
Diesel engine pollutant emissions legislation is becoming more and more stringent. New driving cycles, including increasingly severe transient engine operating conditions and low ambient-temperature conditions, extend considerably the engine operating domain to be optimized to attain the expected engine performance. Technological innovations, such as high pressure injection systems, Exhaust Gas Recirculation (EGR) loops and intake pressure boosting systems allow significant improvement of engine performance. Nevertheless, because of the high number of calibration parameters, combustion optimization becomes expensive in terms of resources. System simulation is a promising tool to perform virtual experiments and consequently to reduce costs, however models must account for relevant in-cylinder physics to be sensitive to the impact of technology on combustion and pollutant formation. In particular, soot is one of the major pollutants of Diesel engines and its kinetic is highly dependent on local mixture properties into the cylinder. This is a challenge for 0-Dimensional (OD) combustion approaches, as it implies 3-Dimensional (3D) phenomena. In this work, to tackle this aspect, the 0D Dual Flame Model (DFM) combustion model was enriched with quasi dimensional features based on the conceptual spray combustion model proposed by Sandia National Laboratories (SNL). This allows to identify local key phenomena depending on mixture thermochemical properties driving soot kinetics. The model was tested on a comprehensive experimental database generated at IFP Energies nouvelles (IFPEN), to investigate the capability of the new approach to predict the impact of engine operating conditions, injection strategy and dilution rate on soot emissions. The quality of the results and the reduced computational time make this approach suitable for engine design and control activities.
\end{abstract}

\section{Introduction}

Severer constraints on pollutant emissions and fuel consumption led Compression Ignition (CI) Diesel engine manufacturers to develop new technologies making more complex the controllability of the overall system. During the calibration phase of the engine, manufacturers have to account for a large number of parameters to reach their targets: injection patterns and phasing, turbocharging behavior, EGR strategies, cooling system control, energy recovery management, etc. Furthermore, due to the increasing synergy between engine combustion chamber and exhaust after-treatment technologies, it is essential to consider global optimization approaches to obtain optimum conditions for meeting high conversion efficiencies in after-treatment systems. Soot is one of the major pollutant species produced by the combustion process of Internal Combustion Engines (ICE), and in particular it concerns Diesel engine architectures. Because of the danger it represents for human health, soot emission legislations are becoming increasingly severe. Moreover, soot is also responsible for thermal losses due to radiative heat exchange with the combustion chamber walls, which impacts the thermodynamic efficiency of the engine cycle and, consequently, the engine fuel consumption $[1,2,3,4]$. To face these challenges, the scientific community and car manufacturers focused their research activities on the understanding of the physical processes holding the soot formation process into the combustion chamber. The present understanding is supported by experimental results $[5,6]$ and detailed Computational Fluid Dynamics (CFD) computations $[7,8]$. Literature studies agree on the complexity of soot formation process and kinetics, especially in Diesel engines, where they take place in a stratified mixture, in terms of temperature and composition, at high-temperature and high-pressure conditions; furthermore, these processes involve thousands of chemical species at different phase states. Despite the potential of the experimental and numerical approaches, limits are reached in both of them, mainly due to resources limitations. Regarding experiments, full metal engine test bench facilities allow to obtain steady-state engine-operatingcondition soot-emissions as a function of the engine calibration; nevertheless, such a tests do not give access to the visualization of the physics taking place into the reactive mixture originating soot. The visualization of the physics requires optical access facilities which, in turn, often operate far from the real-engine in-cylinder conditions. However, both of those approaches are not suitable for engine calibration purposes, due to the large number of engine parameters to be optimized. CFD is a complementary tool to experiments, as it gives a deeper insight of the complex physical processes occurring in the combustion chamber. Nevertheless, to model accurately soot kinetics, two major physical aspects still limit an intensive use of these techniques:

- $\quad$ gaseous phase chemistry must account for hundreds of species and thousands of reactions to be able to predict soot precursors formation,

- multi-phase mechanisms, responsible for the evolution of soot particles during the combustion process, such as nucleation, coalescence, coagulation or surface growing must be correctly described; this requires to have access to detailed information about the mass and the size of soot particles in the reactive mixture.

Both these aspects highlight the need for important and costly computational resources. For this reason, to fill the gap between experiments and 3D CFD computations, OD and Quasi-Dimensional (QD) combustion models are very promising tools $[9,10,11,12,13]$. They proved to be of fundamental importance by providing additional information to the raw experimental results, acquired at the test bench facilities, and allowing more consistent physical interpretations of cause and effect relationships between the main

Page 1 of 19 
engine calibration parameters and combustion and pollutant formation processes. Today, these techniques are complementary and allow to improve the understanding of soot formation. Recent experiments performed at SNL [14,15] and at IFPEN [16] aimed to improve the phenomenological Diesel spray model based on the conceptual model of Direct Injection (DI) Diesel combustion proposed in $[17,18]$. By mean of optical techniques such as Laser Induced Incandescence (LII) and Laser Extinction Method (LEM), it was possible to identify a correlation relying local spray features to soot formation/oxidation activities. The good correlation and consistency shown by those findings opened new perspectives for developing and integrating soot kinetics approaches into QD phenomenological combustion models. In [11] it was shown the potential of having a phenomenological description of the spray to allow a pertinent modeling of soot kinetics. However, the proposed approach was not integrated into a fully OD physical combustion model, limiting the available information about combustion feeding the soot model. Furthermore, the work focused on a limited number of engine operating conditions, adopting single injection and no EGR strategies. Since then, new experiences were performed and the SNL phenomenological model of Diesel spray was improved $[14,18,19]$. In the present work, a detailed phenomenological spray model for modern Diesel engines, as proposed in $[13,20]$, was integrated into the DFM combustion model developed at IFPEN [21]. The implemented approach was thought to integrate as much as possible the specificities of the physics holding soot kinetics: this includes fuel properties and detailed thermochemical properties of the reactive mixture, but also the phenomenology related to sprays evolutions and combustion, and injection-to-injection interactions. These features make it relevant for modern Diesel engine architectures applications, which, in order to deliver the best engine performance, require the integration of EGR loops and high pressure DI systems able to perform shaped and multiple injection strategies. At this development stage, the goal of the model is to determine qualitative soot emission trends as a function of engine calibration variations, in a reasonable computational time. This performance makes the model suitable for engine design and engine control development activities.

\section{Modeling approach}

The developed soot model was integrated into the DFM combustion model [21]: a physical 0D combustion model for Diesel applications, developed and continuously improved at IFPEN. The DFM formalism allows to represent with good accuracy the in-cylinder combustion process scenario, by accounting for the first order relevant physics impacting fuel oxidation. Such an approach presents several advantages: first, it allows to account for the impact of engine actuators on combustion (e.g. injection systems performing complex injection strategies, low pressure and high pressure EGR loops,...) and then to describe the pollutant emissions formation processes, like $\mathrm{CO}$ and NOx, whose chemical kinetics depends strongly on the incylinder thermochemical conditions. According to [15], to get access to the thermochemical mixture properties holding the soot kinetics, a spray-model for modern Diesel engines based on the approach proposed in $[13,20,22]$ was integrated into the DFM model to enrich the combustion scenario description given by the model. This spray model showed its potential for simulations of Diesel sprays, for single injection but also multiple injection strategies, for which injection-to-injection interactions cannot be neglected. The soot kinetics approach, integrated into the proposed spray model to describe soot production/destruction source terms, was inspired by the one proposed in [11], but modified to account for soot efficiency production and to make it suitable to describe combustion processes associated to multiple injection patterns. The different key aspects of the developed approach are detailed below.

\section{Combustion model}

The DFM follows from several years of research in Diesel combustion 0D modeling [12,21,23]. For each separate injection during an engine cycle, the DFM model considers a mixture cloud whose Auto-Ignition (AI) delay is computed. Both types of combustion encountered in CI engines, for all injections occurring during an engine cycle, are considered: a premixed-combustion process followed by a mixing-controlled combustion process. The model considers separate zones for burned and fresh gases. Each zone has its own thermodynamic state and mixture composition. The model uses a twelve-gas formalism to characterize the composition of each zone. This allows to account for $\mathrm{CO}$ and NOx kinetics. More information about the DFM combustion model can be found in [21].

\section{Soot model}

The soot modeling approach retained in this work is based on the conceptual model of DI Diesel combustion originally proposed in [5] and then perfected by recent understanding achieved at SNL and IFPEN [6,18,24,]. It requires the knowledge of key local thermochemical properties of the spray, such as liquid penetration, gaseous penetration, lift-off length, etc. This information allows to compute local mixture compositions and temperatures, which are directly related to soot production and consumption. Further developments made the model suitable to simulate soot kinetics for engine operating conditions accounting for multiple injection strategies. The Diesel surrogate fuel used in this work is the DFL1, a surrogate generated at IFPEN characterized by the molecule C14.9H29.8. At present in the DFM, the developed spray model is dedicated to the computation of soot kinetics and it is only weakly coupled to the combustion heat release modeling ${ }^{1}$. All these aspects are detailed below.

\section{Spreading angle}

The spray-development modeling is based on the assumption of momentum conservation $[17,25,26]$. In fact, for Diesel applications, for which ambient gas densities are high and fuel droplet diameters are small (few micrometers), it is reasonable to suppose that fuel droplets and ambient gas have the same speed along the spray axis, and that the droplets momentum is transferred to the ambient gas without losses. When liquid fuel is injected into an ambient gas, divergence of the jet occurs. The spreading angle is determined by the turbulent entrainment of air into the spray region. Air entrainment results from shear stresses at the spray/ambient gas interface, which implies that it takes place mostly at the lateral surface of the spray. It depends on injector nozzle geometry (i.e. hole diameter and orifice aspect ratio), and fuel and ambient gas densities. The fuel fluid dynamics through the injector orifice is not completely understood today. Accordingly, the analytical expression of the spreading angle, Equation 1, proposed in [27], is an empirical correlation, function of

\footnotetext{
${ }^{1}$ While the computed combustion scenario feeds the spray and indirectly the soot kinetics model, there is no retroaction of soot kinetics on combustion heat release rate computation.
} 
the influencing parameters, that allows to have an estimate of the experimental spreading angle, $\theta$ :

$$
\tan \left(\frac{\theta}{2}\right)=c\left[\left(\frac{\rho_{a}}{\rho_{F_{l}}}\right)^{0.19}-0.0043\left(\frac{\rho_{F_{l}}}{\rho_{a}}\right)^{0.5}\right]
$$

where $\rho_{a}$ is the ambient gas density, $\rho_{F_{l}}$ is the injected liquid fuel density and $c$ is a constant modeling the impact of the injector orifice geometry on the spreading angle. Authors recommend $c=0.26$. The first term of Equation 1 takes into account the spreading-angle density-dependence, while the second term the contraction of the spray induced by the cooling of the entrained hot air. The spreading angle in the model, $\alpha$ in Figure 1, must be related to the measured angle, $\theta$, in order to benefit of the correlation expressed by Equation 1. By making the assumption of self-preserved flow in the spray, the tangents of these two angles are proportional one to the other:

$$
\tan \left(\frac{\alpha}{2}\right)=a \tan \left(\frac{\theta}{2}\right)
$$

the value of $a$ depends on the assumption retained to describe the velocity distribution of the gas over a cross section of the spray; in the case of a uniform velocity distribution assumption, the value $\mathrm{a}=0.75$ was recommended in [28].

\section{Fuel evaporation and liquid penetration}

The evaporation of the liquid fuel in the combustion chamber is the first and one of the most important aspects that must be handled in Diesel combustion modeling. Injected liquid fuel entrains hot ambient gas into the spray region, which allows its evaporation. Intuitively, the major factors that influence the rate of evaporation of a given mass of fuel are:

- injected fuel temperature,

- liquid/gas interface surface extent,

- ambient-gas temperature, pressure and composition,

- $\quad$ slip velocity between liquid fuel and surrounding gas.

In the case of mixing controlled evaporation, as it is the case in Diesel engines, the local interphase transport rates of mass, momentum and energy that control liquid breakup and droplet evaporation must be fast relatively to turbulent mixing rates. In this limit, no local velocity or temperature differences exist between the phases in the spray, and locally the phases are in equilibrium [29]. Accordingly, turbulent mixing controls vaporization by determining the rate at which energy is entrained into the spray for heating and vaporizing the fuel. In turbulent mixing controlled regime, the influence of diameter and velocity droplet distributions on the evaporation process can be neglected. In [27] a scaling law describing the liquid penetration in the combustion chamber, calibrated on experiments, is proposed. By definition at a liquid penetration $x=L$, the fuel is completely vaporized and at thermodynamic equilibrium with the ambient gas (fuel saturation condition), Figure 1. The non-dimensional liquid-phase penetrationlength, $\tilde{L}$, is obtained from Equation 3 for the coordinate $x=L$ :

$$
\tilde{L}=b \sqrt{\left(\frac{2}{B}+1\right)^{2}-1}
$$

where $b$ is a constant coefficient, authors recommend $b=0.41$, and the variable $B$ corresponds to the transfer number at the liquid/gas interface of the evaporating droplets. According to the hypotheses of the liquid length model, that is equilibrium at the interface, $B$ represents both mass and thermal transfer numbers, $B_{T}$ and $B_{M}$, respectively [24]. The dimensional expression of the liquid-phase penetration, $L$, is then obtained as:

$$
L=\tilde{L} x^{+}
$$

where the penetration length scale, $x^{+}$, is defined as:

$$
x^{+}=\sqrt{\frac{\rho_{F_{l}}}{\rho_{a}}} \frac{d_{v c}}{\tan \left(\frac{\alpha}{2}\right)}
$$

with the diameter of the vena contracta, $d_{v c}$, defined as:

$$
d_{v c}=\sqrt{C_{a}} d_{h}
$$

in which $C_{a}$ is the area contraction coefficient and $d_{h}$ is the injector holes diameter.

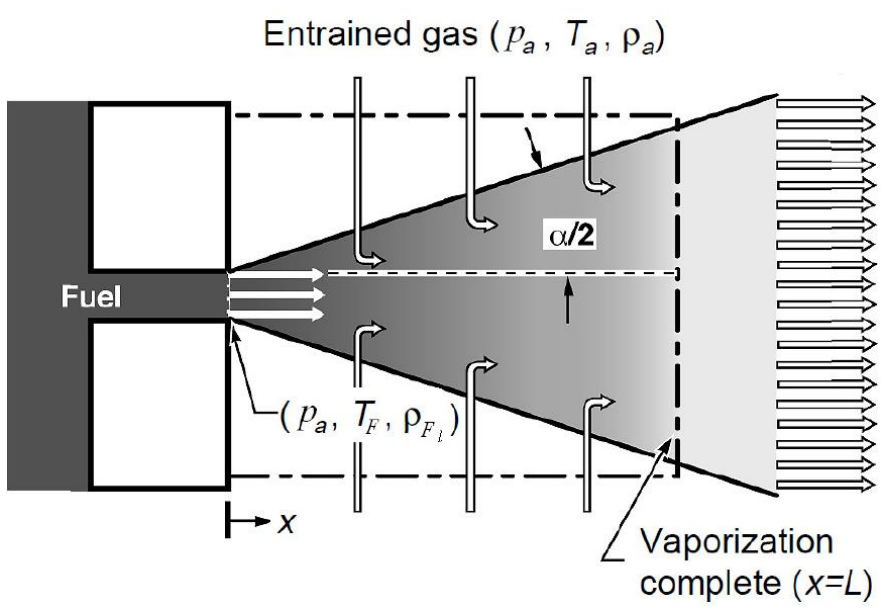

Figure 1. Schematic of the idealized spray model used to develop the liquid length scaling law [27].

\section{Gas penetration}

To describe the gaseous phase penetration, $S$, the retained approach was the one proposed in [17]. This approach reflects the fact that spray dynamics depends on momentum balance and, accordingly, it makes explicit the dependence between the spray opening angle and the spray penetration. Similarly to liquid length penetration, a scaling law was proposed to compute a non-dimensional gaseous penetration, $\tilde{S}$ : 


$$
\tilde{S}=\left(\left(\frac{1}{\tilde{t}}\right)^{n}+\left(\frac{1}{\sqrt{\tilde{t}}}\right)^{n}\right)^{-\frac{1}{n}}
$$

in which $n$ is a constant coefficient, authors recommend $n=2.2$, and $\tilde{t}$ represents a non-dimensional time defined as:

$$
\tilde{t}=\frac{t}{t^{+}}
$$

where $t$ is the physical time from the Start Of Injection (SOI) and $t^{+}$is a time scale defined as:

$$
t^{+}=\frac{x^{+}}{U_{e f f}}
$$

in which $U_{\text {eff }}$ represents the effective injection velocity computed as:

$$
U_{e f f}=\frac{4 \dot{m}_{F_{i n j}}}{\rho_{F_{l}}\left(C_{a} C_{v} n_{h} \pi d_{v c}^{2}\right)}
$$

where $\dot{m}_{F_{i n j}}$ is the liquid fuel mass flow rate exiting from injector, $C_{v}$ is the velocity coefficient accounting for the non-uniform velocity profile, and $n_{h}$ is the injector hole number. Then, physical spray penetration can be retrieved by mean of the following relation:

$$
S=\widetilde{S} x^{+}
$$

Figure 2 shows the model capability to predict spray penetrations in a constant volume vessel for different thermodynamic conditions of the ambient gas within the vessel.

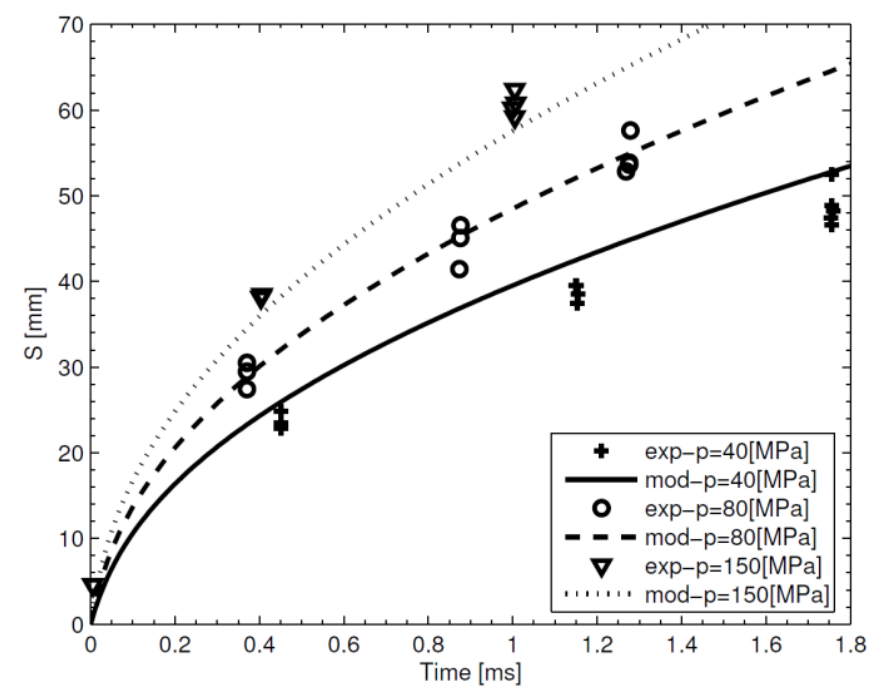

Figure 2. Gaseous-phase spray tip penetration. Experimental conditions: fuel=n-heptane, $T_{a}=387 \mathrm{~K}, \rho_{\mathrm{a}}=25 \mathrm{~kg} / \mathrm{m}^{3}$ and $\mathrm{d}_{\mathrm{h}}=200 \mu \mathrm{m}$. Comparison of computed spray penetrations with experimental data obtained in a high pressure vessel by [30].

Page 4 of 19

\section{Lift-off length}

The above sections explained how to characterize the mixture formation process within the spray region; this aspect has in fact a relevant influence on the combustion process and in particular on the lift-off length setting up. The lift-off length $(l o l)$ is defined as the distance between the nozzle tip and the most upstream-jet combustion location, corresponding to the lifted diffusion flame anchoring distance [24]. A relation coherent with the spray theory proposed in [31] that allows to compute the $l o l$, was proposed in [32]:

$$
l o l=C_{l o l} C_{\text {exp }} U_{e f f} T_{a}^{-3.74} \rho_{a}^{-0.85} d_{h}^{0.34} Z_{s t}^{-1}
$$

where $C_{l o l}$ is a calibration constant of the model, $C_{\text {exp }}$ is a proportionality factor that was determined experimentally in [28], $C_{\text {exp }}=7.04 \mathrm{e} 8, T_{a}$ is the ambient gas temperature and $Z_{s t}$ is the fuel mixture fraction at stoichiometry. The knowledge of the lol together with the fuel injection pattern and the air entrainment within the spray region upstream the lol allows to determine the thermochemical properties of the mixture at $l o l$, which, according to [5,6,33], is the region where soot precursors are formed. More recently, $[15,18]$ showed that fuel/air equivalence ratio at lol can be, with good accuracy, correlated to the soot volume fraction.

\section{Soot kinetics}

At $l o l$, mixture burns at rich equivalence ratios in premixed-flamelike combustion-process; combustion products then cross the spray to be eventually fully oxidized in a diffusion flame at the periphery of the spray. In this scenario, the Polycyclic Aromatic Hydrocarbons $(\mathrm{PAH})$, soot precursors, are formed at the lol and then convected through the Diesel spray, where they mix with the hot combustion products producing then soot. Soot accumulates at the jet tip to be then oxidized by the diffusion flame [5,6]. Accordingly, lol is determinant for the characterization of soot formation. According to the approach proposed in [28], the mean equivalence ratio at $l o l, \phi_{l o l}$, can be univocally determined. Recently, the model improvements proposed by [14] allow to determine not only the mean equivalence ratio at a given axial coordinate of the spray, but also to have access to the velocity and fuel distribution profiles along the radial coordinate of the spray. This allows the computation of the equivalence ratio at $l o l$ on the axis of the spray, $\phi_{l o l}^{0}$ :

$$
\phi_{l o l}^{0}=C_{d i s t r} \frac{2 A F R_{s t}}{\left(\sqrt{1+16\left(\frac{l o l}{x^{+}}\right)^{2}}-1\right)}
$$

where $A F R_{s t}$ is the stoichiometric air/fuel ratio by mass and $C_{d i s t r}$ is a coefficient that allows to pass from the mean spray cross section value of equivalence ratio at $l o l$ to the value of equivalence ratio along the spray axis. According to [14]., $C_{\text {distr }}=1.3$. To describe soot kinetics by taking into account the above depicted combustion scenario, the retained approach was inspired by the one proposed by [11], built, in turn, on the model proposed by [34]. Equation 14 describes the net soot mass variation within the combustion chamber: 


$$
\frac{d m_{\text {soot }}}{d t}=\left.\frac{d m_{\text {soot }}}{d t}\right|_{p}-\left.\frac{d m_{\text {soot }}}{d t}\right|_{o}
$$

In Equation 14, the first RHS term represents the soot production contribution, while the second RHS term represents the soot oxidation contribution; those terms are detailed by Equation 15 and Equation 16, respectively. Concerning soot production:

$$
\left.\frac{d m_{s o o t}}{d t}\right|_{p}=C_{s p} \eta_{\phi} \phi_{l o l}^{0} m_{F_{d \dot{f}}} p^{0.5} e^{\frac{-E_{s p}}{R T_{s p}}}
$$

where $C_{s p}$ is a calibration constant to adjust the model behavior to different fuels and engines, $\eta_{\phi}$ is an efficiency factor varying in the interval $[0,1]$, which enables soot production; $\eta_{\phi}$ passes from one to zero by means of a smoothed transition function when $\phi_{l o l}^{0}$ values pass below the value of two, according to experimental results shown in $[18,28] . m_{F_{d i f}}$ represents the mass of fuel within the combustion chamber available to burn in diffusion combustion [21], $p$ is the incylinder pressure, $E_{s p}$ is the activation energy of the soot production reaction $\left(E_{s p}=52335 \mathrm{~J} / \mathrm{mol}\right), R$ is the perfect gas constant and $T_{s p}$ represents the adiabatic temperature of combustion at $l o l$, relative to a fresh gas composition having fuel/ambient gas composition (in the most general case ambient gas is made of air, burned gas and diluent) and a temperature equal to that of vaporization (temperature at the liquid/gas interface) [24]. Concerning soot oxidation:

$$
\left.\frac{d m_{\text {soot }}}{d t}\right|_{o}=C_{s o} m_{s} Y_{02_{s t}} p^{1.8} e^{\frac{-E_{s o}}{R T_{s o}}}
$$

where $C_{s o}$ is a calibration constant to adjust the model behavior to different fuels and engines, $m$ represents the mass of soot within the combustion chamber, $Y_{O_{s t}}$ is the oxygen mass fraction at stoichiometric conditions, $E_{s o}$ is the activation energy of the soot oxidation reaction $\left(E_{s o}=58615 \mathrm{~J} / \mathrm{mol}\right)$ and $T_{s o}$ represents the adiabatic temperature of combustion in the region where soot is oxidized, that is the temperature relative to a stoichiometric diffusion flame, whose fresh gas temperature was assumed to be the same as the temperature of the soot formation region. Once all of the fuel is consumed, the oxidation of soot becomes dependent upon the bulk mean temperature and oxidation is quenched when the bulk mean temperature drops below $1000 \mathrm{~K}$ [35].

\section{Multiple injection considerations}

The approach retained to model injection-to-injection interactions was the one developed in [22,36]. Figure 3 illustrates how, for a case of multiple injection, injections sprays interact with each other, and shows the information made available by the approach. In details, the injected fuel of the i-th injection penetrates within the combustion chamber and evaporates to form the i-th spray region; by assuming a conical spray shape, by means of Equation 11, it is possible to compute a spray volume and its temporal derivative, to have access to ambient air entrainment, $\dot{m}_{a_{i}}$, within the spray region, Figure 3. From a spray geometrical-development viewpoint, within the combustion chamber, it is assumed that injections sprays follow the same path and, growing within the cylinder, interact with each other. This

Page 5 of 19 allows to compute, continuously, for each injection, mean composition and equivalence ratio of the spray.

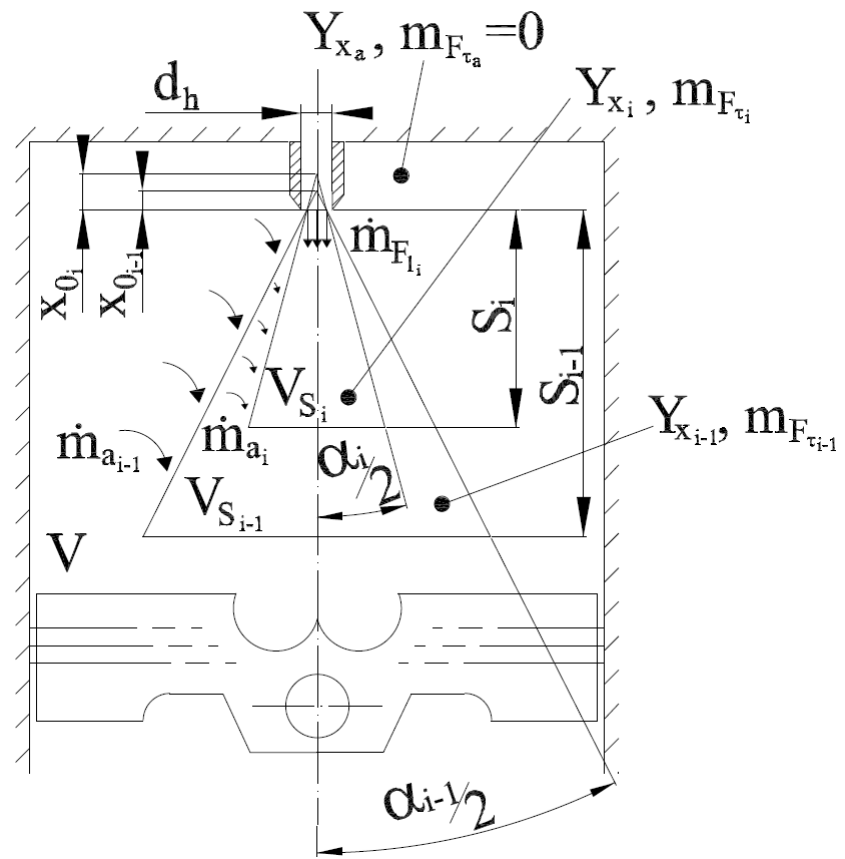

Figure 3. Schematic of the multiple injection modeling approach. V is the cylinder volume, subscript $i$ refers to the $i^{\text {th }}$ injection, $V_{S}$ represents the spray volume, $Y_{x}$ represents the mass fraction of the species $x$, subscript $a$ indicates ambient gas and subscript $\tau$ indicates tracer variables which, by definition, are combustion independent [22].

In combustion scenarii adopting multiple injection strategies, it is assumed that soot production is associated to thermochemical conditions characterizing the latest injection.

\section{Model validation and discussion}

To validate the developed approach to soot modeling, experimental data generated at IFPEN relative to a 4-cylinder DI Diesel engine were used. The engine specifications are given in Table 1 .

Table 1. Multi-cylinder DI Diesel engine used for the soot model validation.

\begin{tabular}{|l|l|}
\hline Displaced volume & $2300 \mathrm{cc}$ \\
\hline Stroke & $101.3 \mathrm{~mm}$ \\
\hline Bore & $85 \mathrm{~mm}$ \\
\hline Connecting Rod & $157.3 \mathrm{~mm}$ \\
\hline Compression ratio & $16: 1$ \\
\hline Number of valves per cylinder & 4 \\
\hline Injection system & Piezoelectric \\
\hline
\end{tabular}

99 Engine Operating Points (EOP), representative of a complete engine map, with engine speed varying between 1000 and $2750 \mathrm{rpm}$ and engine load ranging from 1 bar to full load were retained in this study, Figure 4. The engine is equipped with a high pressure EGR system which allows to attain up to $50 \%$ of EGR rate. Figure 5 shows for which operating points the EGR strategy is activated, and the level of EGR rate. Multiple injection strategies were adopted over the 
whole engine map: a single pilot plus main injection-strategy for the lower loads, and a double pilot plus main injection-strategy for the higher loads, Figure 6.

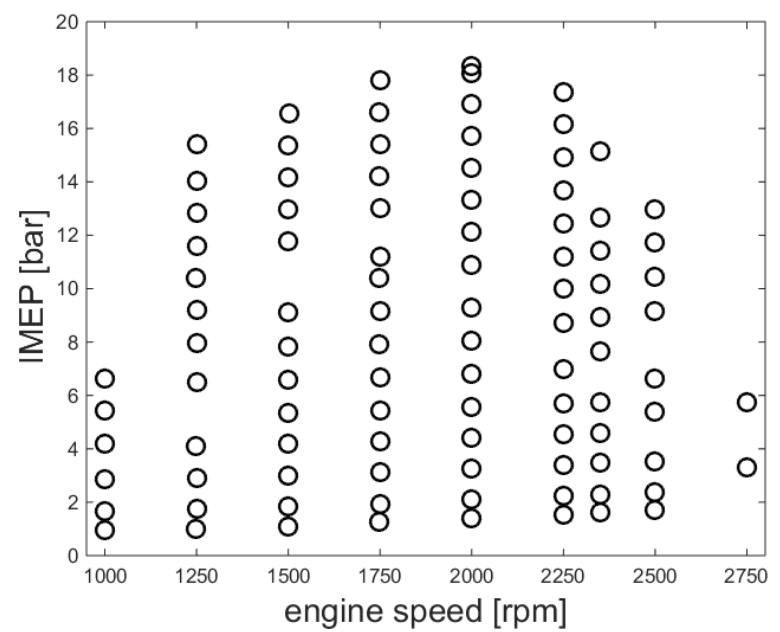

Figure 4. Investigated EOPs of the multi-cylinder DI Diesel engine.

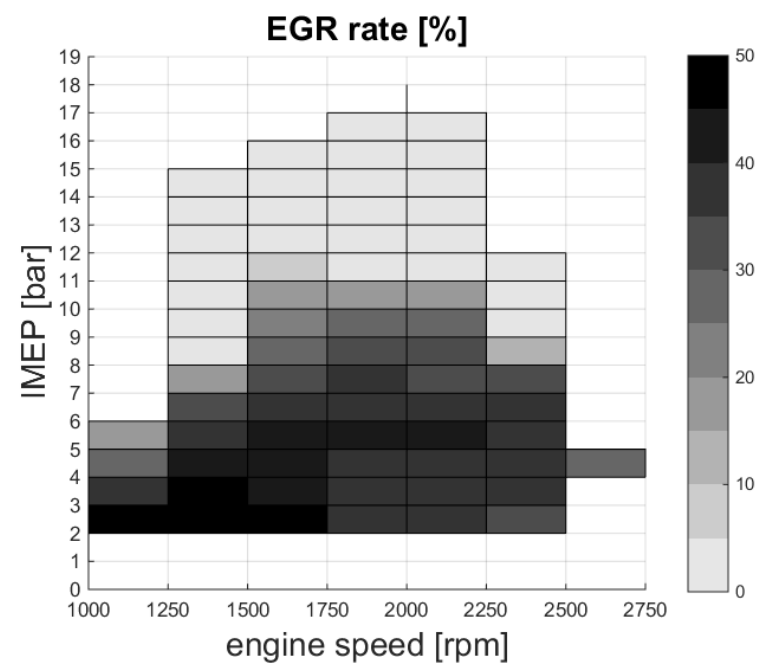

Figure 5. EGR strategy definition for the multi-cylinder DI Diesel engine.

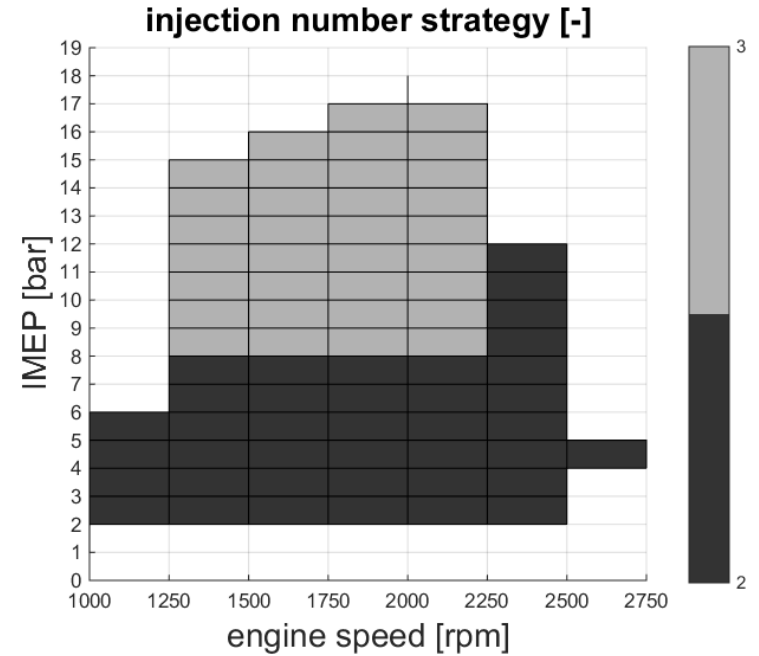

Figure 6. Injection strategy definition for the multi-cylinder DI Diesel engine.

The combustion process relative to experimental conditions were computed by the DFM combustion model. For this, the DFM was integrated into a numerical LMS Imagine.Lab Amesim ${ }^{\mathrm{TM}}$ simulator representative of a single-cylinder engine, as shown in Figure 7.

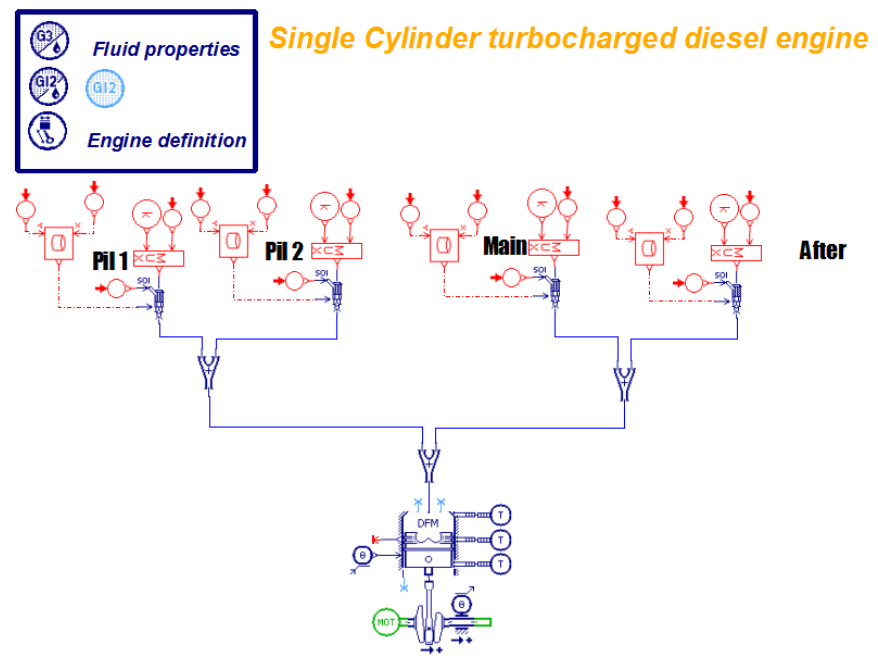

Figure 7. Single-cylinder engine simulator used for the DFM combustion process computations.

\section{Model calibration and simulation results}

In this section the methodology used to calibrate the DFM combustion model and the new soot model will be presented, as well as the results obtained over the complete engine operating domain, Figure 4.

\section{Combustion model calibration}

As a first step, the DFM combustion model was calibrated by using the automatic calibration process detailed in [21]: it consists in a four-steps sequential calibration process (1/AI; 2/combustion; 3/CO emission; 4/NOx emission) allowing to determine all parameters of the combustion and pollutant models, exception done here for the 
soot model. The accuracy of simulation results relative to the investigated domain depends on the number and on the distribution on the domain of the operating points used for calibrating the model. In this work, as the goal was the development and the validation of a soot model, the complete engine map was used to calibrate at best the combustion process. The optimized combustion model parameters values are presented in Table 2.

Table 2. Optimized DFM parameters for the multi-cylinder DI Diesel engine.

\begin{tabular}{|c|c|c|}
\hline AI & $k_{A I_{-} I}$ & 1.7 \\
\hline \multirow{2}{*}{ Step 1} & $k_{A I_{-} 2}$ & 3.22 \\
\hline & $k_{\text {mag }}$ & 5000.0 \\
\hline \multirow{8}{*}{ Combustion } & $C_{\text {turb }}$ & 2.0 \\
\hline & $C_{\text {diss }}$ & 0.068 \\
\hline & $C_{k}$ & 2.5 \\
\hline & $C_{g}$ & 7.98 \\
\hline & $C_{\text {prem }}$ & 0.75 \\
\hline & $C_{m u l}$ & 5503.8 \\
\hline & $\alpha_{\text {res }}$ & 0.41 \\
\hline & $C_{m i x}$ & 3.5 \\
\hline \multirow[b]{2}{*}{$\mathrm{CO}$} & $E_{a} C O$ & 8057.5 \\
\hline & $A_{t} C O$ & 9990.0 \\
\hline \multirow{3}{*}{ Step 3} & $E_{a a} C O$ & 11992.5 \\
\hline & $A_{t t} C O$ & 0.00057 \\
\hline & $F A R_{\text {diff }}$ & 0.98 \\
\hline \multirow{2}{*}{ NO } & Coeff ${ }_{G F G B}$ & 0.0068 \\
\hline & $E_{a} N O$ & 7266.9 \\
\hline \multirow{4}{*}{ Step 4} & $A_{t} N O$ & 0.5 \\
\hline & $E_{a a} N O$ & 9519.0 \\
\hline & $A_{t t} N O$ & 0.47 \\
\hline & $B G R_{N O x}$ & 3.56 \\
\hline
\end{tabular}

\section{Combustion model results}

Final results after the combustion model calibration are reported in Figure 8 to Figure 15. In the figures, the 99 points are sorted in ascending engine-speed order, Figure 8 (above). As shown in Figure 8 to Figure 13, the combustion process is correctly simulated, as the simulations predict with good accuracy Indicated Mean Effective Pressure (IMEP), Figure 8 and Figure 9, peak in-cylinder pressure, Figure 10 and Figure 11, and peak in-cylinder pressure location, Figure 12 and Figure 13.
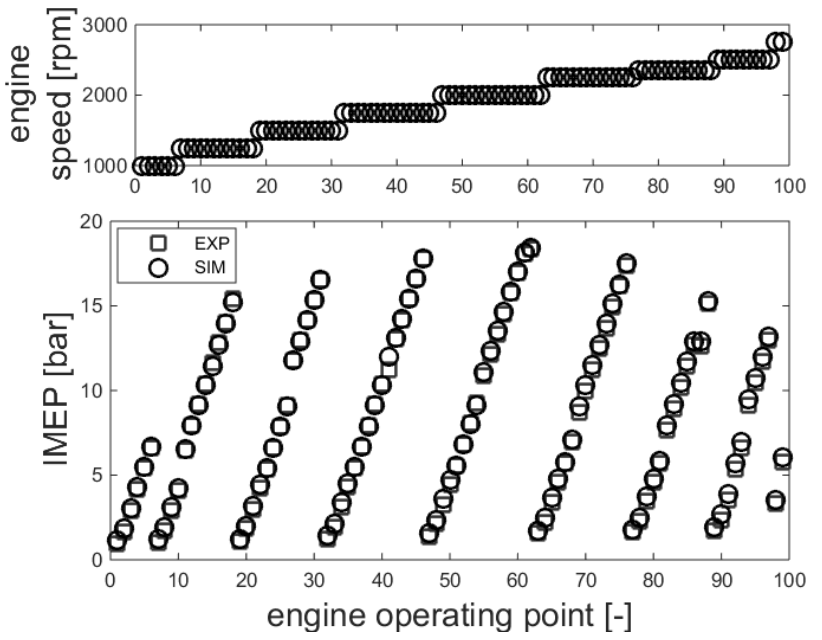

Figure 8. Simulation results over the complete engine map: engine speed (above) and IMEP (below).

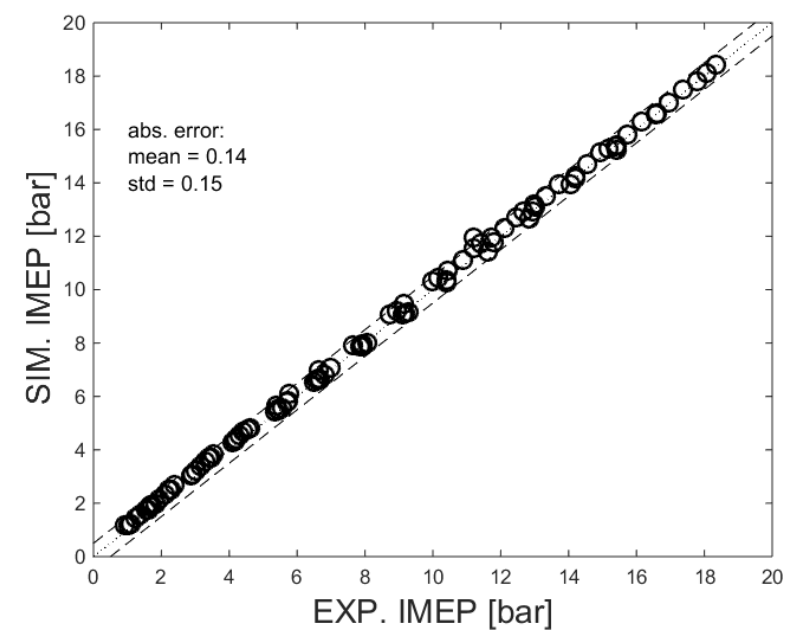

Figure 9. Comparison of IMEP simulation results with experiments. Dashed lines represents +/-0.5 bar error bars; error type and statistics are given in the figure.

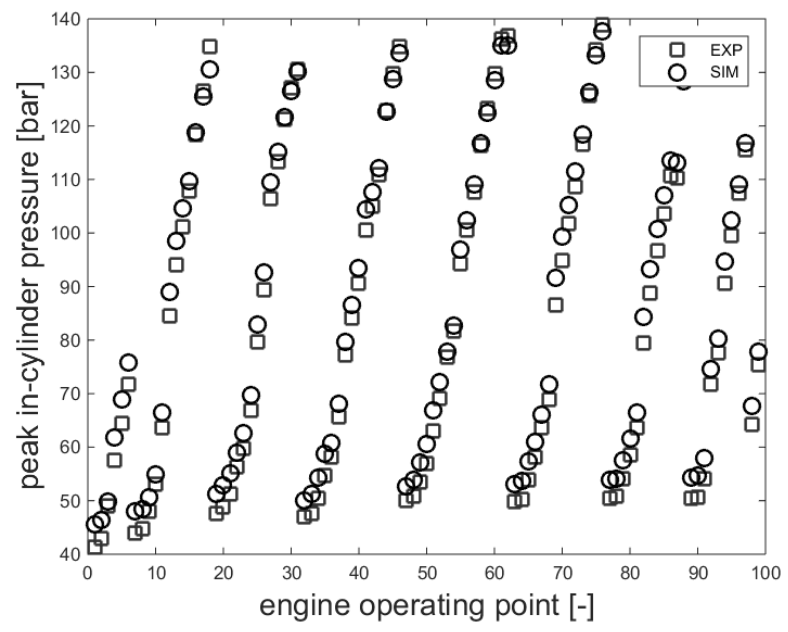

Page 7 of 19 
Figure 10. Simulation results over the complete engine map: peak in-cylinder pressure.

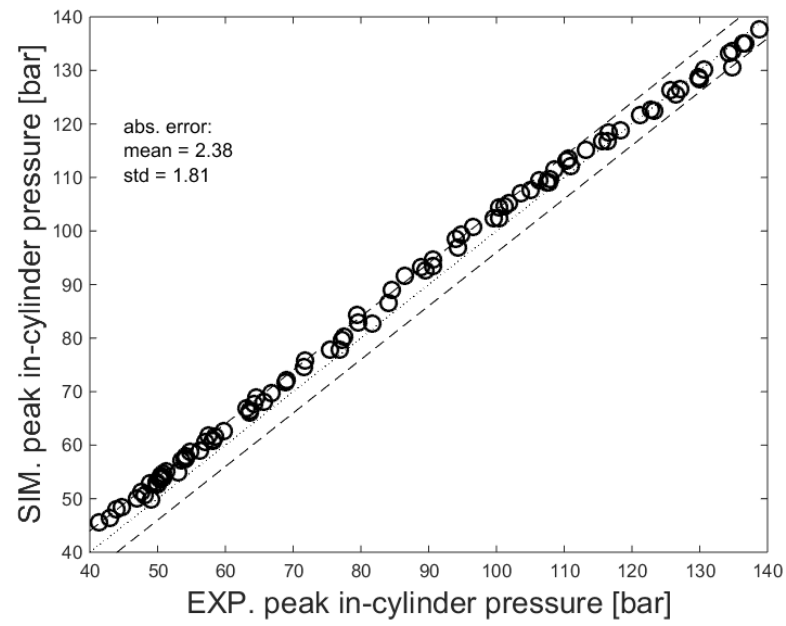

Figure 11. Comparison of peak in-cylinder pressure simulation results with experiments. Dashed lines represents +/-4 bar error bars; error type and statistics are given in the figure.

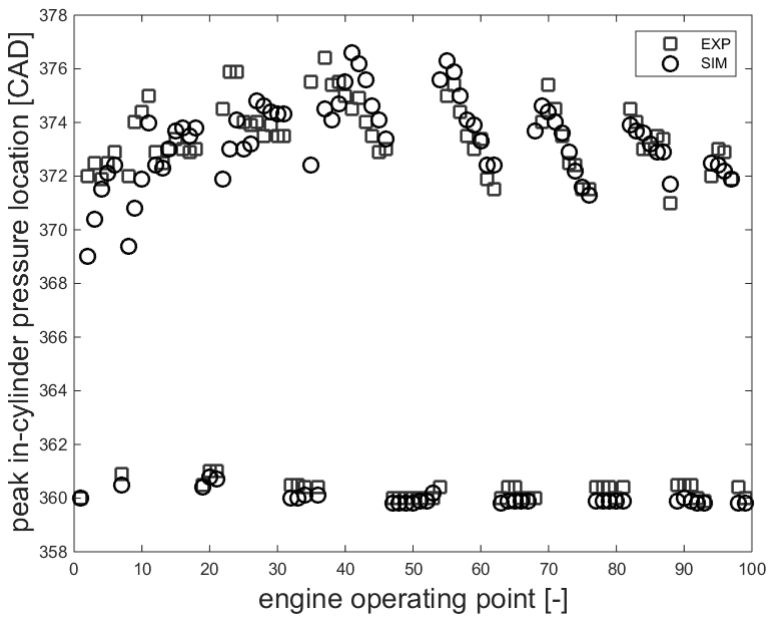

Figure 12. Simulation results over the complete engine map: peak in-cylinder pressure location.

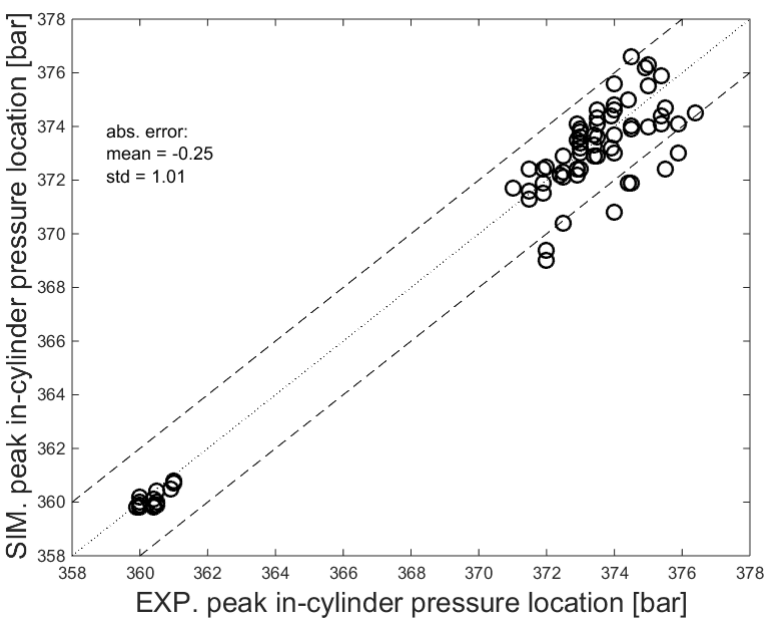

Figure 13. Comparison of peak in-cylinder pressure location simulation results with experiments. Dashed lines represents +/-2 CAD error bars; error type and statistics are given in the figure.

Good agreement between simulation results and experiments was also found for dry NOx emissions, Figure 14 and Figure 15; this, being NOx emissions computations based on the thermochemical properties of the burned gas zone in the combustion chamber, supports the representativeness of the combustion scenario depicted by the DFM model within the combustion chamber.

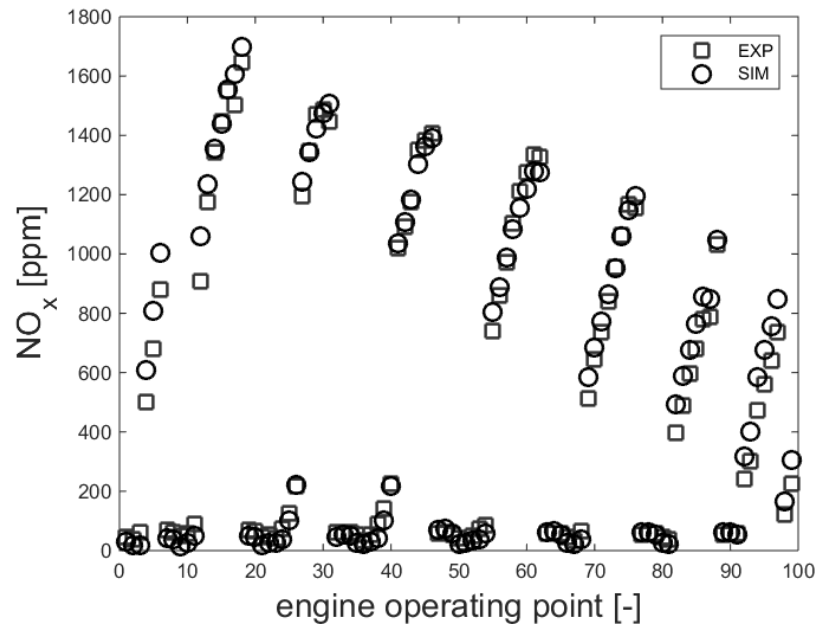

Figure 14. Simulation results over the complete engine map: dry NOx emissions. 


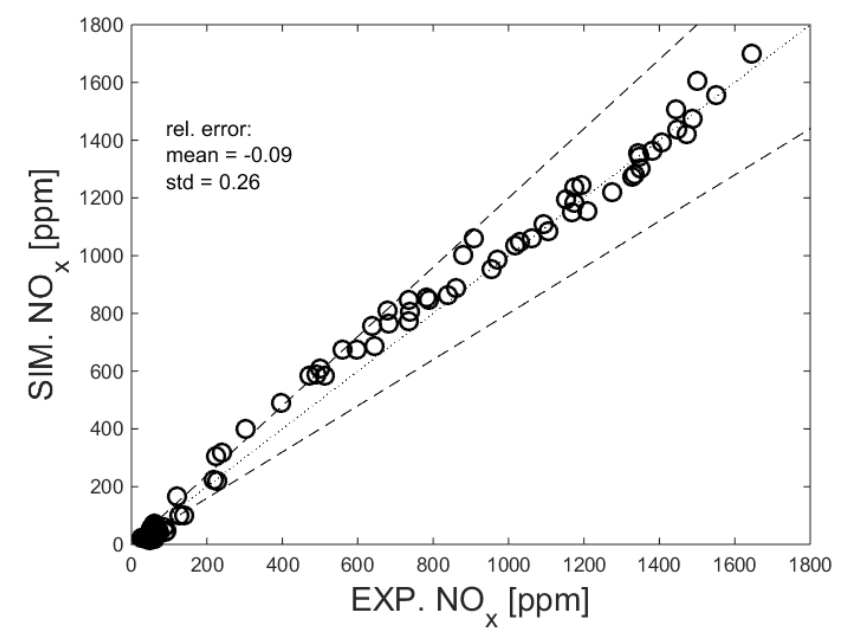

Figure 15. Comparison of NOx emission simulation results with experiments. Dashed lines represents $+/-20 \%$ error bars; error type and statistics are given in the figure.

\section{Soot model calibration}

The soot model presented above has to be calibrated to account for engine geometry and fuel formulation. For this, in the model formulation equations, several calibration parameters were introduced. However, some of these values were specified in the literature to best fit, with the proposed model, experiments. In this work, because of the lack of intermediate experimental results to get a deeper insight of the different physical phenomena occurring in the combustion chamber, those values were kept unchanged ${ }^{2}$. Regarding the values of the $C_{a}$ and $C_{v}$ coefficients, Equation 6 and Equation 10 respectively, they were defined according to the work presented in [27]: $C_{a}=0.84$ and $C_{v}=0.95$. Being all the engine operating points relative to steady-state engine operating conditions, the temperature of the injected liquid fuel was set arbitrarily to $360 \mathrm{~K}$ for all points. The remaining soot-model parameters were calibrated manually ${ }^{3}$, in order to obtain the best results over the entire investigated engine domain. Their final values are stored in Table 3.

Table 3. Soot-model calibration parameters.

\begin{tabular}{|l|l|l|}
\hline \multirow{3}{*}{ Soot } & $C_{\text {lol }}$ & 0.87 \\
\cline { 2 - 3 } & $C_{s p}$ & 0.66 \\
\cline { 2 - 3 } & $C_{s o}$ & $1.1 \mathrm{e}-7$ \\
\hline
\end{tabular}

2 The soot model constants values that were fixed according to the values given in the literature are specified directly in the text of the paper.

${ }^{3}$ Starting with $C_{l o l}$ equal to unity, $C_{s p}$ and $C_{s o}$ are adjusted to fit at best the soot emission profile, by paying attention to reproduce soot emission peak amplitudes; if minimum values are overestimated / maximum values underestimated $C_{\text {lol }}$ coefficient is increased / reduced to reduce / enhance the soot production; then $C_{s p}$ and $C_{s o}$ are adjusted to fit at best the soot emission profile.

\section{Soot model results}

Final results, after the soot model calibration, are reported in Figure 16 to Figure 20. The 99 points are sorted in ascending engine-speed order, Figure 8 (above). Figure 16 shows the comparison of the experimental soot emissions map versus the simulated soot emissions map. As it is shown, the model is able to quite well detect the engine operating conditions for which soot emissions are more important and localize them on the engine map. For the sake of clarity, the same results comparison is shown in the upper part of Figure 17, by using a different representation, showing soot emissions as a function of the EOPs. In the lower part of Figure 17, the major engine operating condition variables are plotted as well, to facilitate the interpretation of the results. As shown, the model is able to capture from a qualitative viewpoint, but also from an acceptable quantitative viewpoint, the evolutions of soot emissions. In particular it can be observed that the localization of the soot emission peaks and the trends of soot emissions are well represented, despite the fact the highest soot emission peaks are not always well reproduced in absolute values.

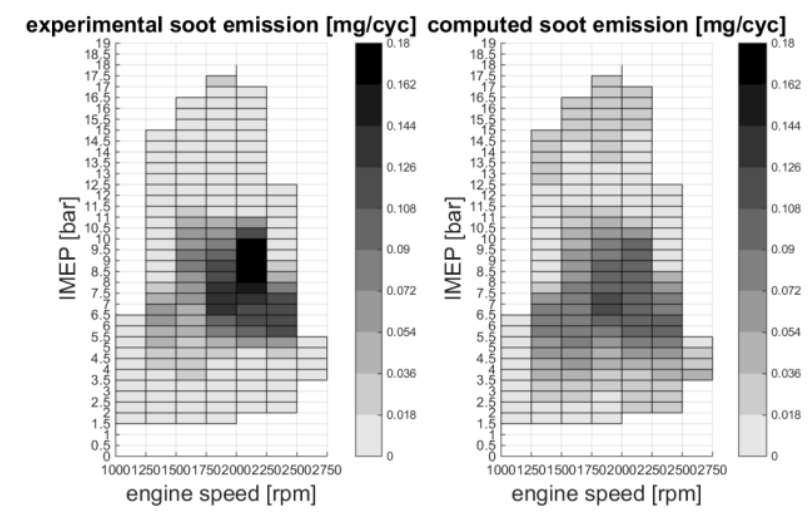

Figure 16. Simulation results over the complete engine map: maps of soot emissions.
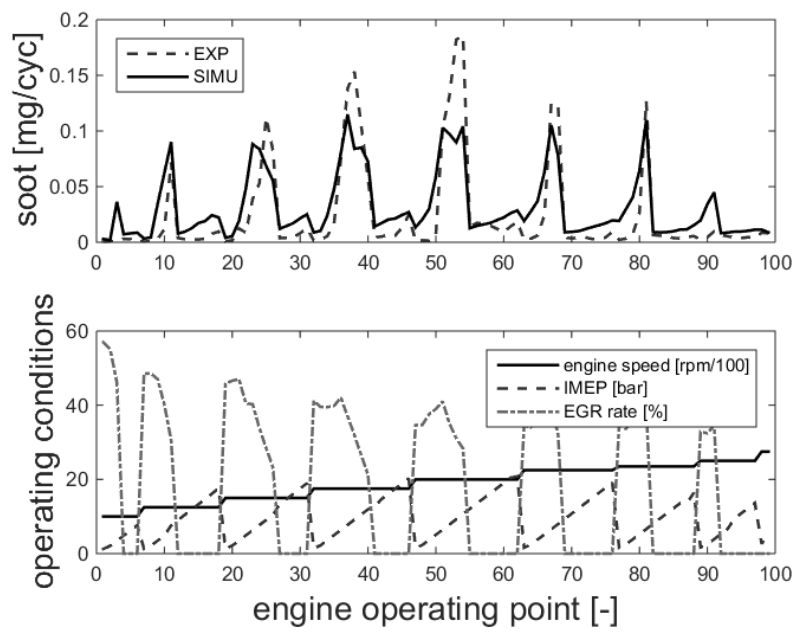

Figure 17. Simulation results over the complete engine map: soot emissions (above); engine operating conditions (below).

Figure 18 shows a scatter plot comparison of soot emission simulation results with experiments. 


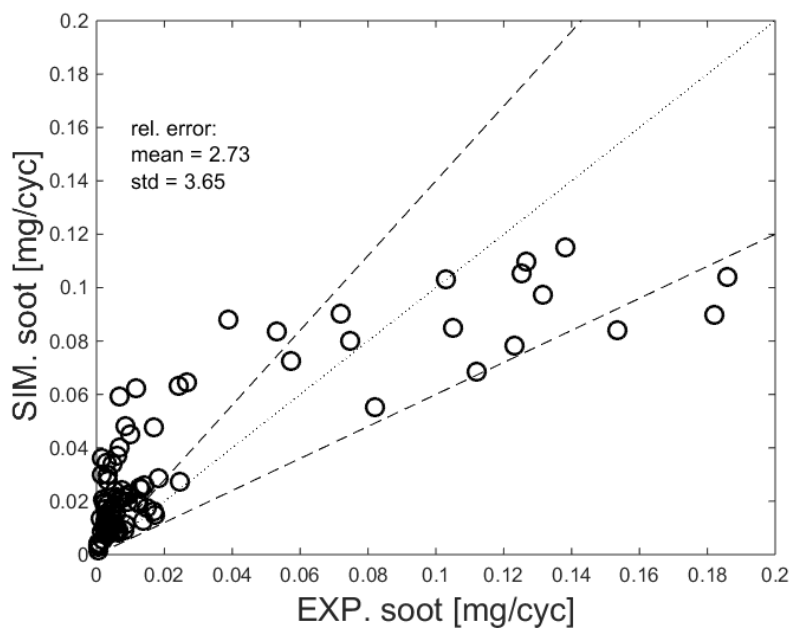

Figure 18. Comparison of soot emission simulation results with experiments. Dashed lines represents $+/-40 \%$ error bars; error type and statistics are given in the figure.

Figure 19 shows the soot emissions versus the EGR rate for all the engine operating domain. It is interesting to note that the model is able to represent the increase of soot emissions with the EGR rate. In the same fashion, Figure 20 shows the soot emissions versus the NOx emissions. Once again, it is interesting to note that the DFM combustion model is able to predict correct estimates for both NOx and soot emissions over the complete engine map, and correlate them consistently with experiments. This represents an interesting potential of the approach to be applied to engine design and engine control development activities.

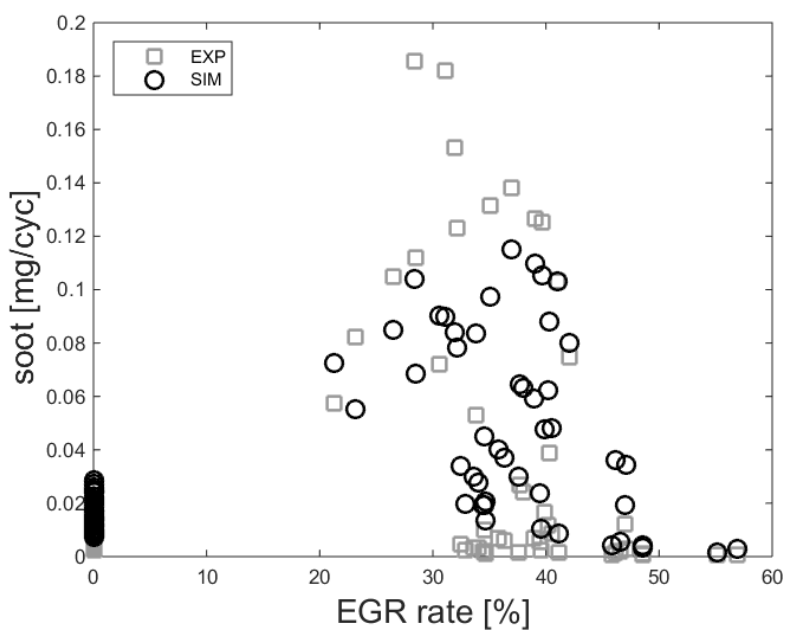

Figure 19. Simulation results over the complete engine map: soot emissions versus EGR rate.

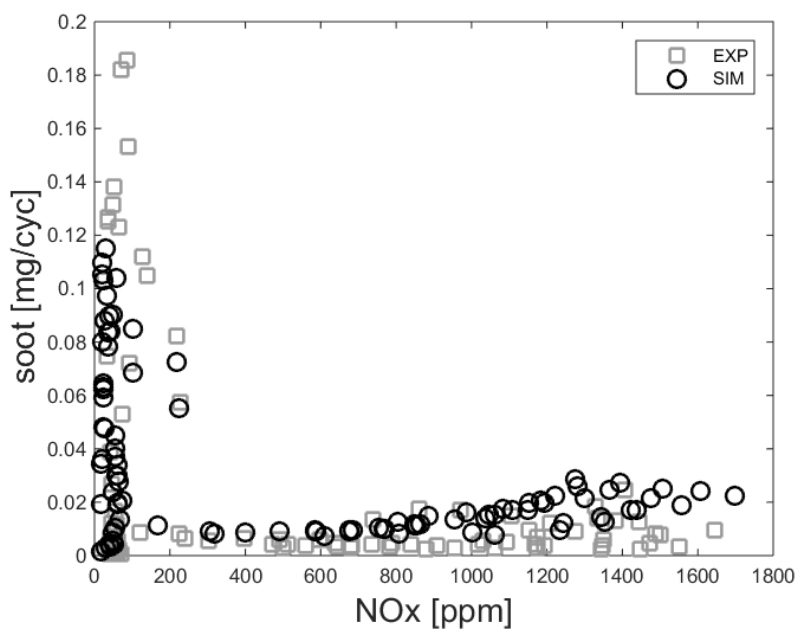

Figure 20. Simulation results over the complete engine map: soot emissions versus NOx emissions.

\section{Soot model sensitivity analysis}

This section is dedicated to the investigation of the response of the developed phenomenological soot model to single-parameter variations, relatively to a given engine operating condition. The study presented below is not supported by experimental data, hence, the model response can only be validated from a qualitative point of view. Nevertheless, the phenomenology described by the model will be analyzed and supported by observations coming from the literature $[18,37,38,39]$. The reference EOP that was retained is the EOP number 39 , characterized by an IMEP $=10.5$ bar, engine-speed $=1750$ rpm and EGR rate $=26.5 \%$; experimental soot emissions for this EOP are $0.105 \mathrm{mg} / \mathrm{cyc}$, which implies an underestimation of the simulated soot emissions of about $18 \%$, Figure 17. Figure 21 to Figure 30 illustrate the combustion scenario relative to the considered EOP and detail the evolution of the different variables allowing to compute soot kinetics. In details, Figure 21 shows that for the considered EOP a double pilot plus main injection strategy was adopted. As shown, the DFM model is able to reproduce quite accurately the Heat Release Rate (HRR) of combustion. Figure 22 shows the mass of liquid fuel per injection within the cylinder. This result together with the one shown in Figure 23, which represents the evolution of the spray volume per injection, which is tightly related to the entrained mass of ambient gas within the spray per injection [20], allows to compute the evolution of the mean equivalence ratio within the spray per injection, Figure 24. It is worth to remark that the model does not account for spray/wall interaction. Accordingly, the spray evolution is representative of a free jet evolution in an ambient gas having the same mean thermodynamic properties of the combustion chamber and the chemical properties of the mean in-cylinder mixture at the beginning of the injection. 

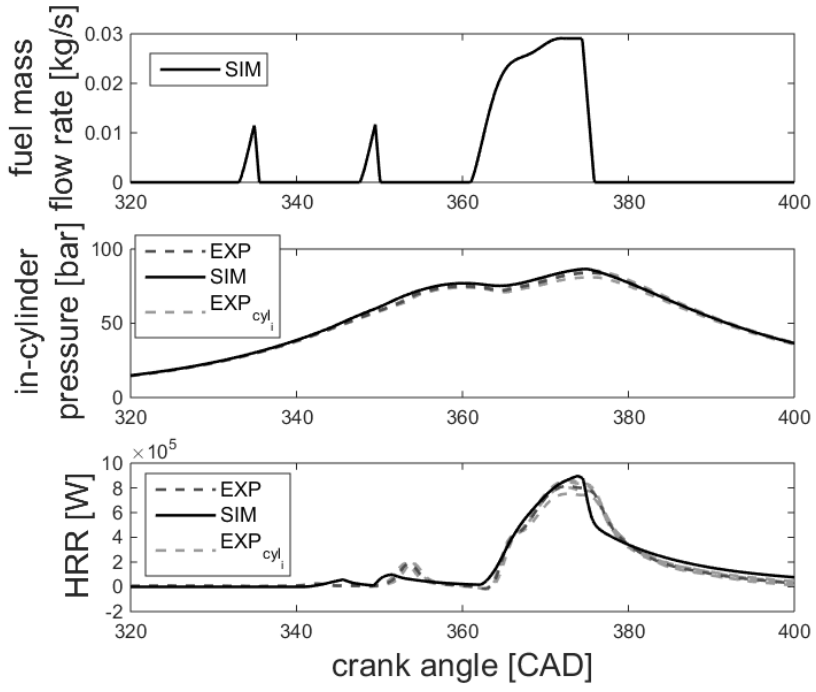

Figure 21. Reference engine operating conditions (EOP \#39): fuel injection strategy (top); in-cylinder pressure (middle); HRR (bottom). Simulation (solid line), cylinder averaged experiment (dark dashed line) and i-th cylinder experiment (pale dashed line).

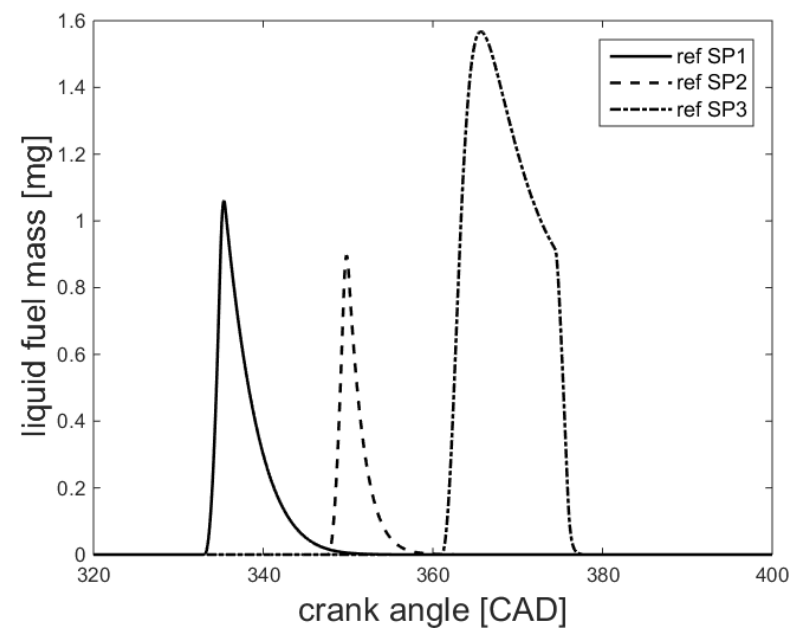

Figure 22. Reference engine operating conditions (EOP \#39): liquid mass of fuel per injection.

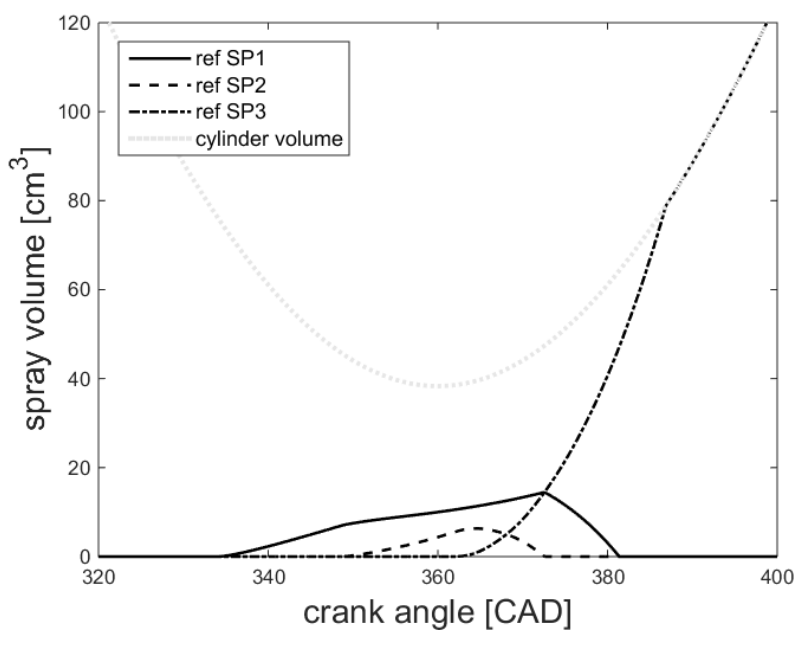

Figure 23. Reference engine operating conditions (EOP \#39): spray volume per injection.

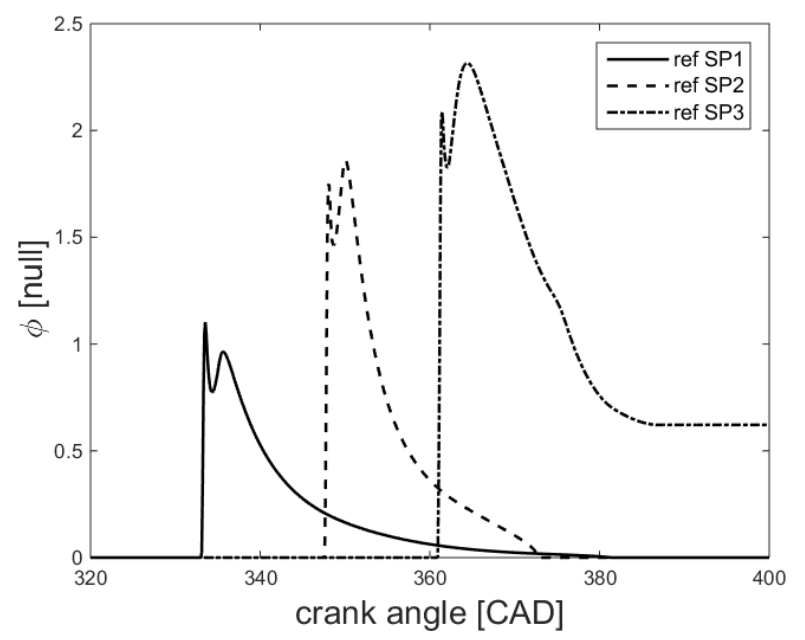

Figure 24. Reference engine operating conditions (EOP \#39): mean spray equivalence ratio per injection.

Figure 25 shows the liquid fuel penetration within the cylinder. As the model does not account for spray/wall interaction, this variable is not impacted by the presence of the piston. As shown, because of the more and more severe thermodynamic conditions of the ambient gas mixture, the liquid penetration continuously reduces. Figure 26 shows the evolution of the lol per injection, while Figure 27 shows the equivalence ratio on the axis of the spray at the lol per injection. 


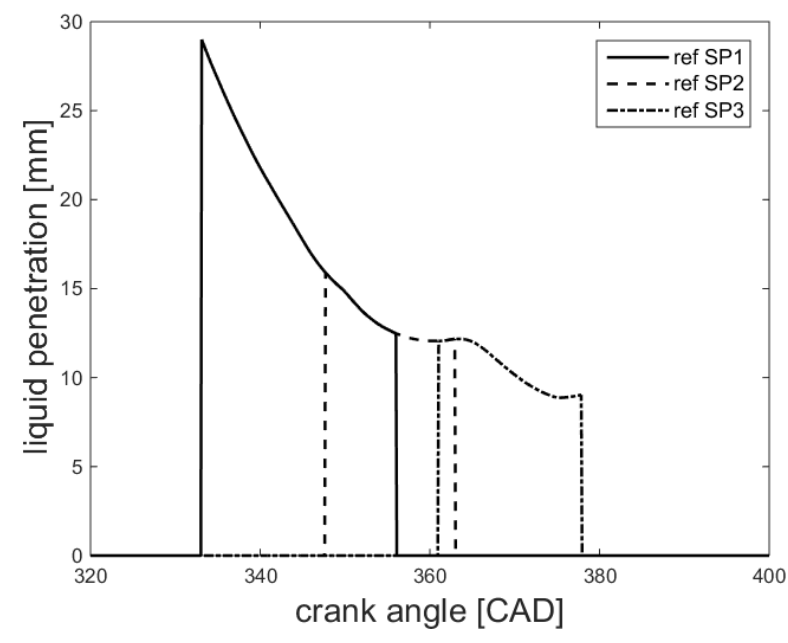

Figure 25. Reference engine operating conditions (EOP \#39): liquid penetration per injection.

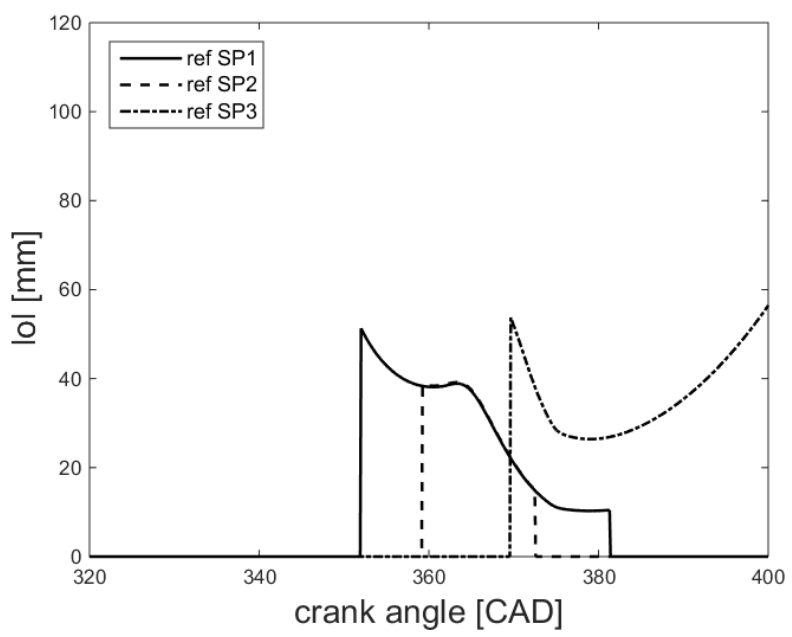

Figure 26. Reference engine operating conditions (EOP \#39): lol per injection.

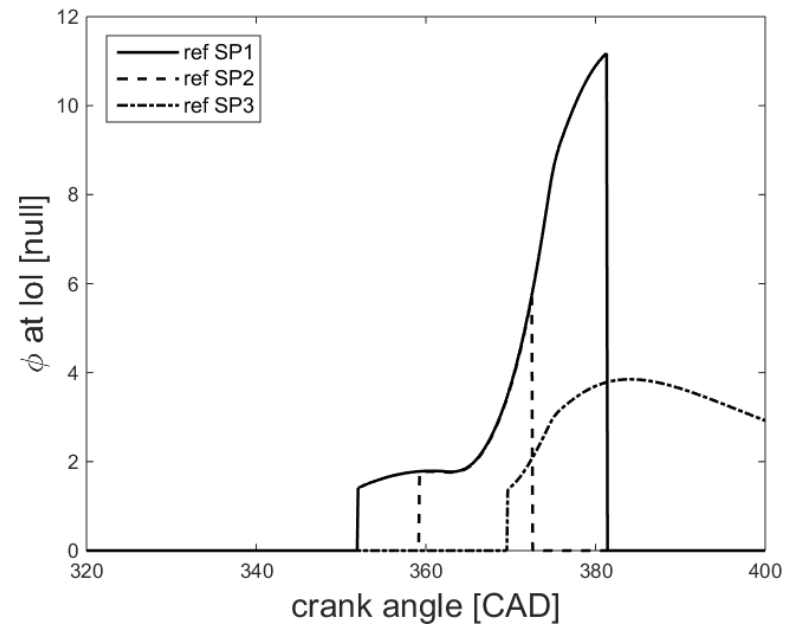

Figure 27. Reference engine operating conditions (EOP \#39): equivalence ratio at lol per injection.

Page 12 of 19
According to [40,41], during the combustion phase in engine configuration, contrarily to the constant volume vessel experiments observations [28], the lol continues to diminish during the injection phase and even during the expansion stroke, when density and temperature decrease. This phenomenon, due to the heating of the entrained ambient gas into the spray region [40,41,42], is well captured by the model, Figure 26. It is worth noting that the high values of equivalence ratios shown in Figure 27 for pilot injections (SP1 and SP2) are purely numerical issues and do not influence soot mass formation; this for two main reasons:

- the masses of involved fuel are very small,

- for that crank angle interval, they are not considered for the computation of soot kinetics, being the conditions at lol of the main injection the ones looked at to determine the soot mass formation, Equation 15.

Figure 28 and Figure 29 respectively show the burned gas temperatures at $l o l$ and at stoichiometric conditions, these temperatures being responsible of soot kinetics of formation and oxidation, respectively.

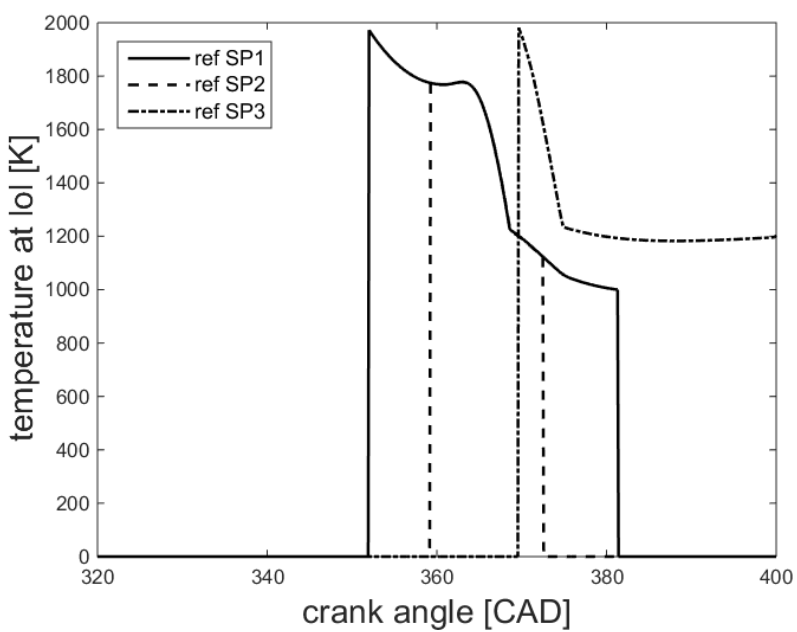

Figure 28. Reference engine operating conditions (EOP \#39): temperature at lol per injection.

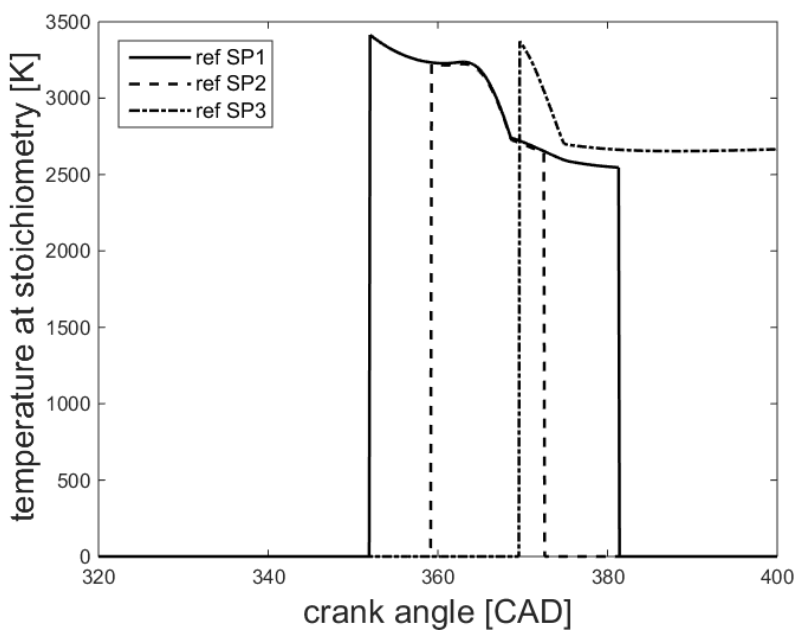

Figure 29. Reference engine operating conditions (EOP \#39): temperature at stoichiometry per injection. 
Finally, Figure 30 shows the evolution of the simulated soot mass within the cylinder for the considered EOP. The presence of the first peak at the beginning of the main-injection combustion process is explained by the high temperature at lol due to the relatively lower equivalence ratio, thus impacting the temperature of soot oxidation at stoichiometry.

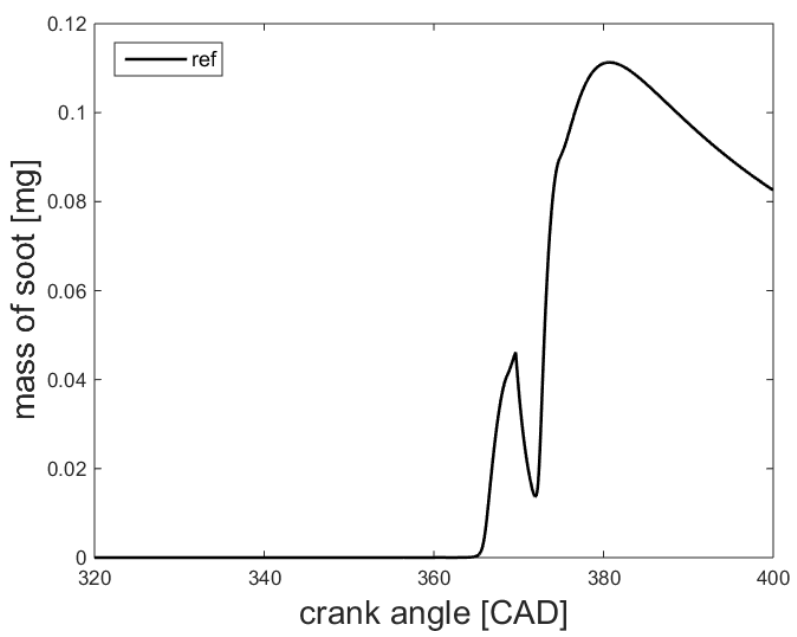

Figure 30. Reference engine operating conditions (EOP \#39): in-cylinder mass of soot.

Based on the reference condition, single parameter variations were performed in order to investigate the impact of possible EOP calibration variations on soot production. These results are presented below.

\section{Injection pressure variation}

In this section, a variation of the injection pressure is operated. Figure 31 shows the impact a variation of the injection pressure has on the injected fuel mass flow rate, while Figure 32 represents the variation of the in-cylinder pressure for the different operating conditions. As shown, an increasing of the injection pressure implies a faster introduction of the fuel mass, bringing to a faster HRR. Accordingly, spray volumes grow faster, Figure 33, and lols increase, as observed in [18,28], Figure 34, with a consequent decreasing of the equivalence ratio at lol, Figure 35, which, in turn, contributes to reduce soot production, Figure 36. Such a physical behavior was also experienced in $[18,37,38]$.

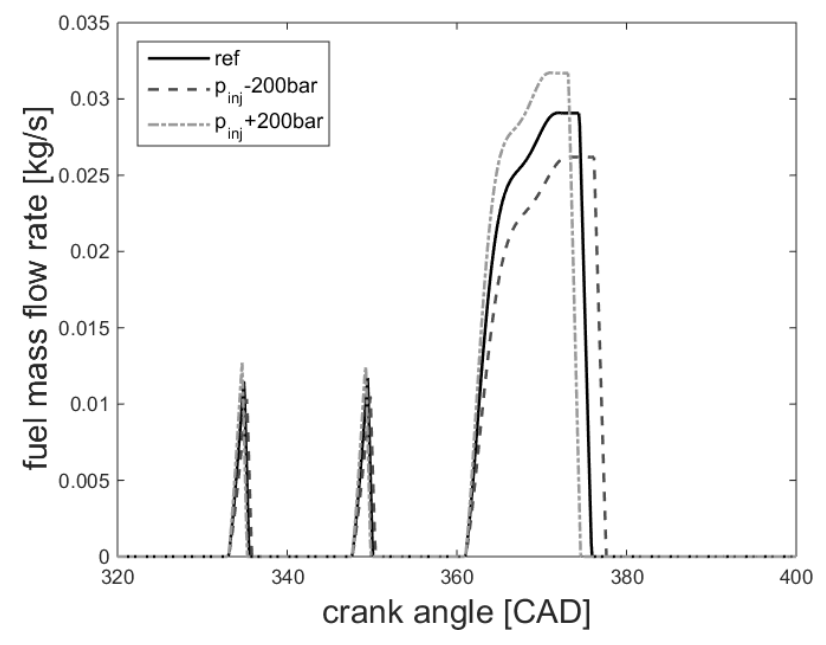

Figure 31. Injection pressure variation: injected fuel mass flow rate.

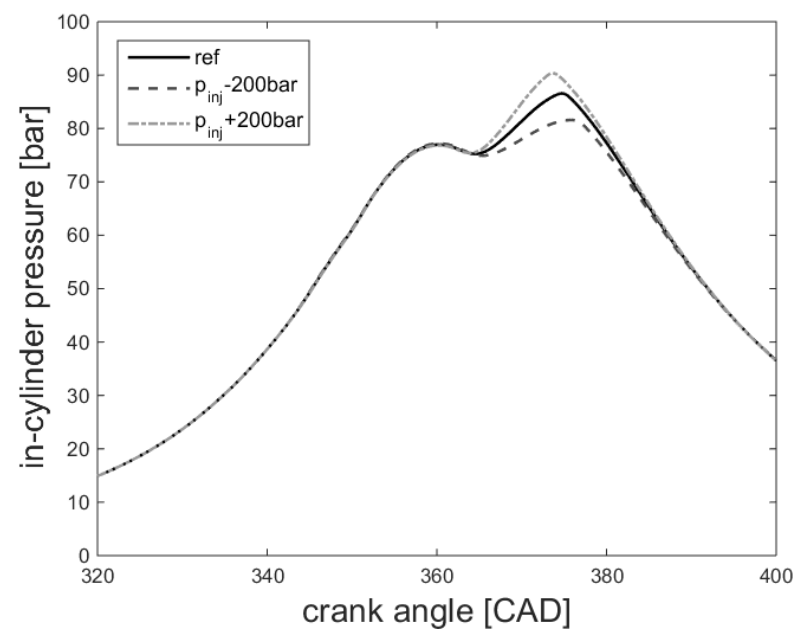

Figure 32. Injection pressure variation: in-cylinder pressure.

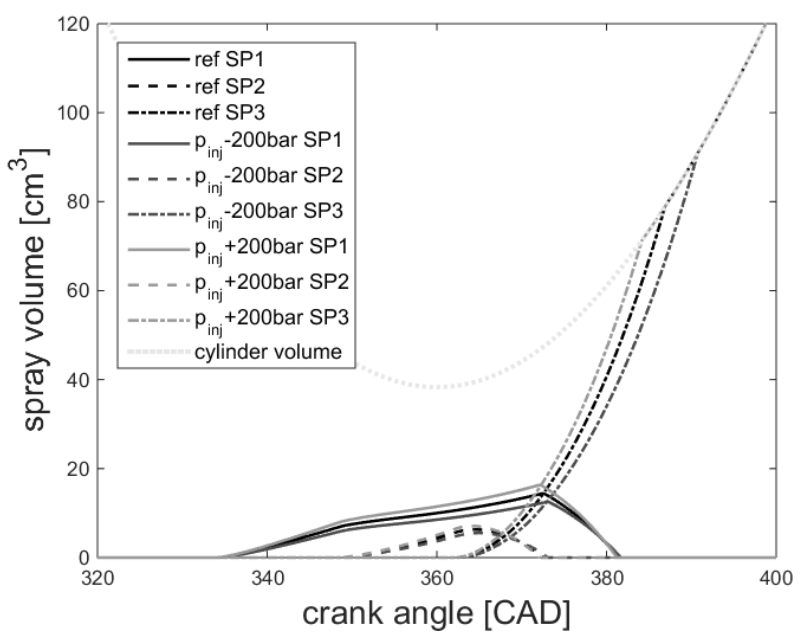

Figure 33. Injection pressure variation: spray volume per injection.

Page 13 of 19 


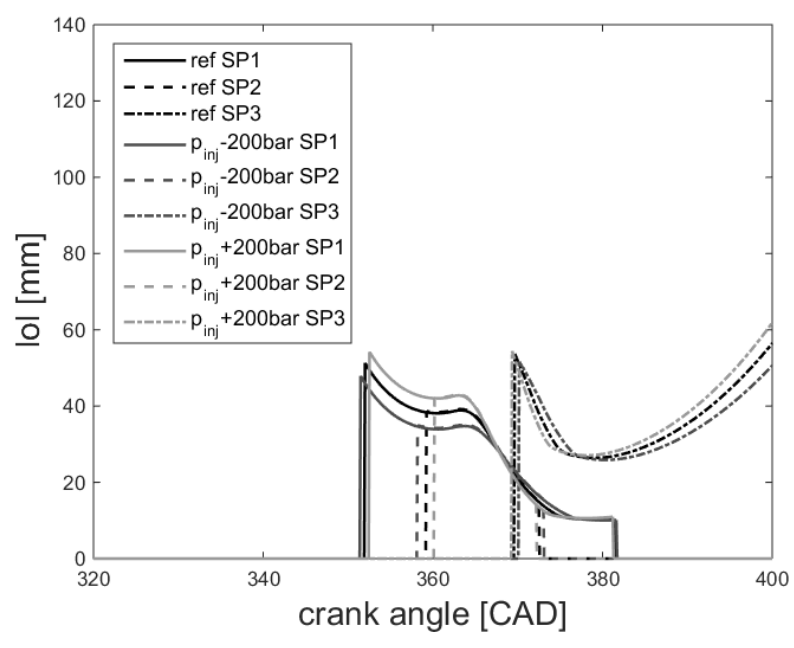

Figure 34. Injection pressure variation: lol per injection.

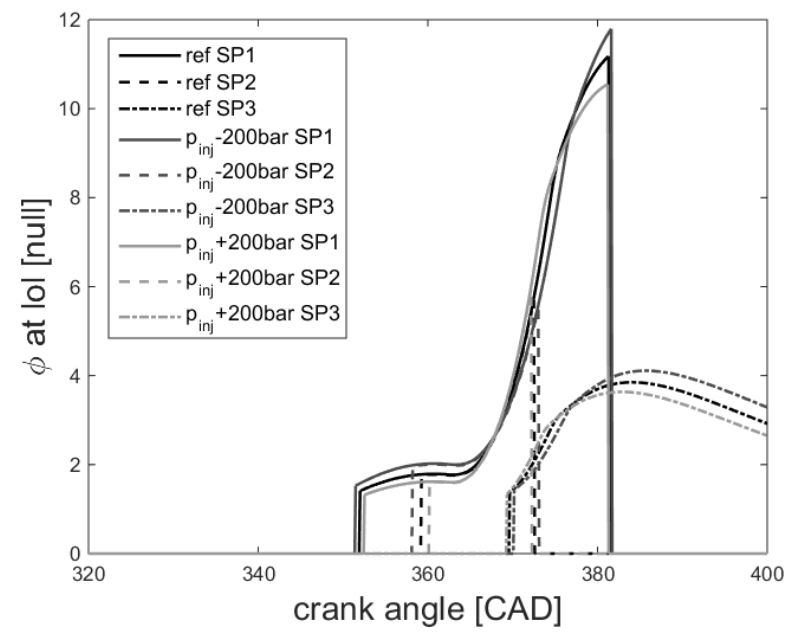

Figure 35. Injection pressure variation: equivalence ratio at $l o l$ per injection.

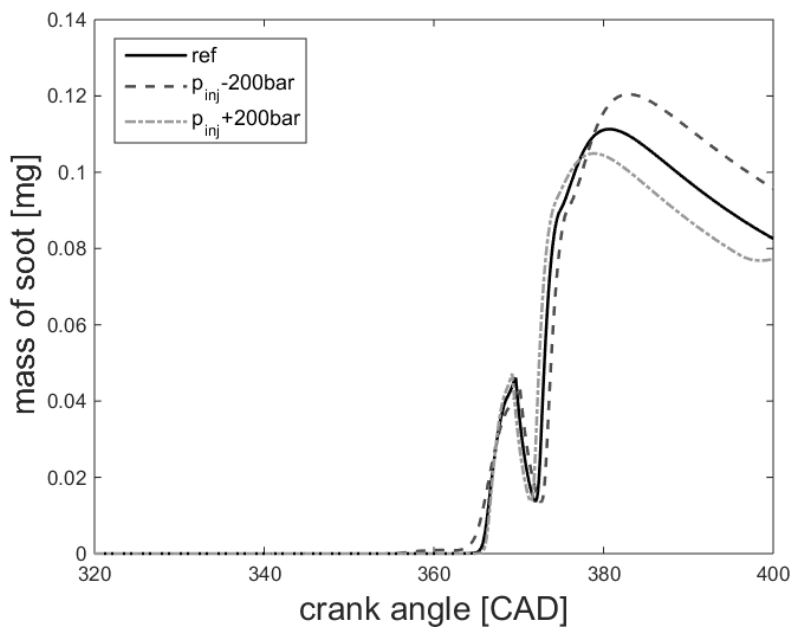

Figure 36. Injection pressure variation: in-cylinder mass of soot.

Page 14 of 19

\section{Main injection SOI variation}

In this section, a variation of injection timing, and in particular of the main-injection SOI, is operated. Figure 37 shows the impact a variation of injection timing has on the in-cylinder pressure for the different operating conditions. As shown, an increasing of the main injection SOI implies a faster HRR due to the more favorable thermodynamic conditions for combustion within the cylinder. According to [38], an increasing of SOI implies a decreasing of soot emissions: this is justified by the fact that the mean temperature within the cylinder is higher and for more time, with a consequent increasing of soot oxidation. The results given by the model confirms such a phenomenology and agree with literature, Figure 38.

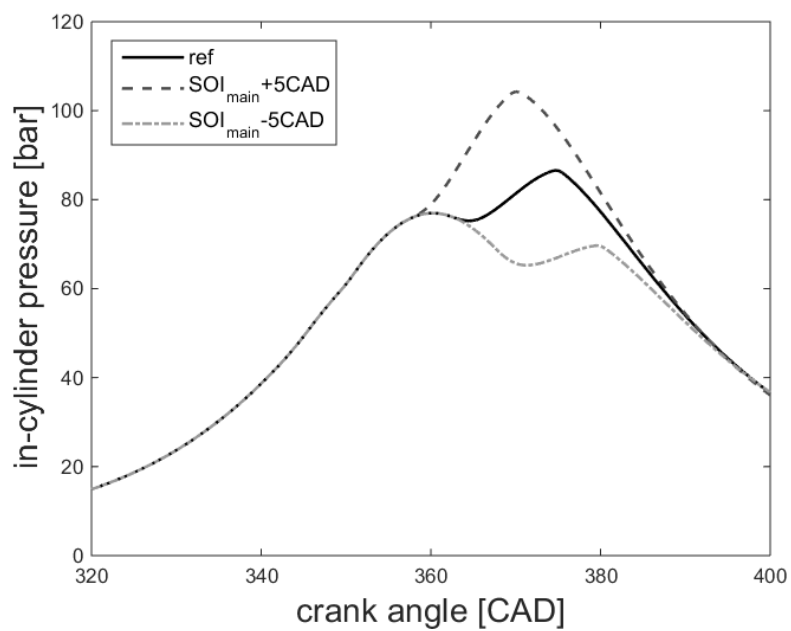

Figure 37. Injection timing variation: in-cylinder pressure.

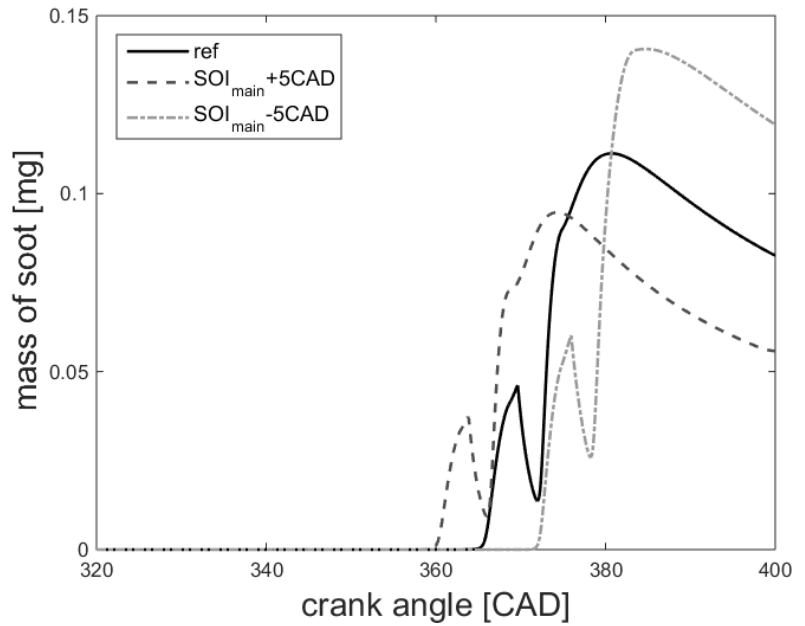

Figure 38. Injection timing variation: in-cylinder mass of soot.

\section{Injection pattern variation}

In this section, a variation of the injection pattern, maintaining unchanged the total injected fuel mass, is operated. In details, three configurations were tested: the reference case, a reduced maininjection case, were both pilot injections masses were increased of 1 $\mathrm{mg}$, and an increased main-injection case, were pilot injections were 
suppressed, Figure 39. Figure 40 shows the impact a variation of the injection pattern has on the in-cylinder pressure for the different operating conditions. As shown, an increasing of the pilot injections fuel masses implies more favorable thermodynamic conditions for the main injection fuel evaporation and combustion, Figure 40, which results in higher in-cylinder temperatures and, consequently, faster soot production and oxidation, Figure 41. This agrees with what was found in [37]. Nevertheless, because of the reduced main-injection fuel mass, the global soot emissions are lower for smaller maininjection masses.

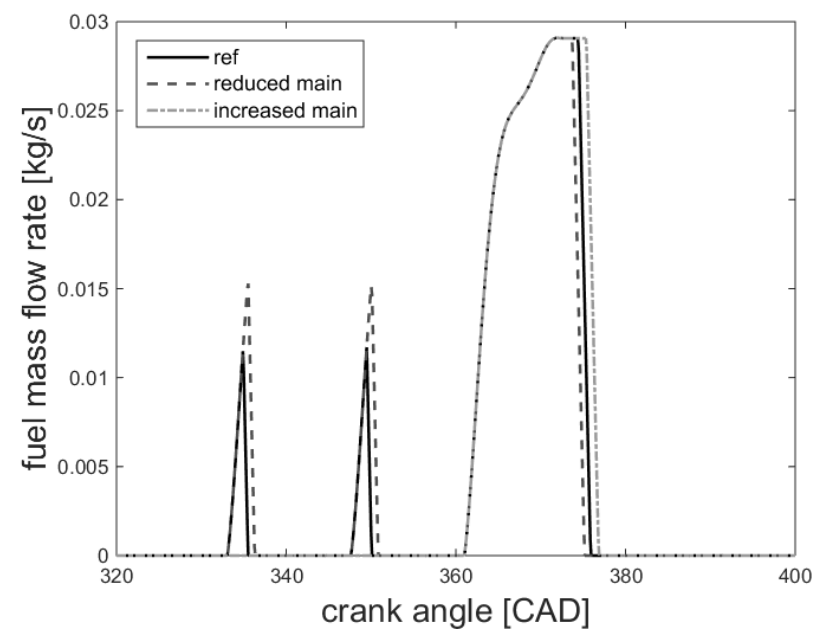

Figure 39. Injection pattern variation: injected fuel mass flow rate.

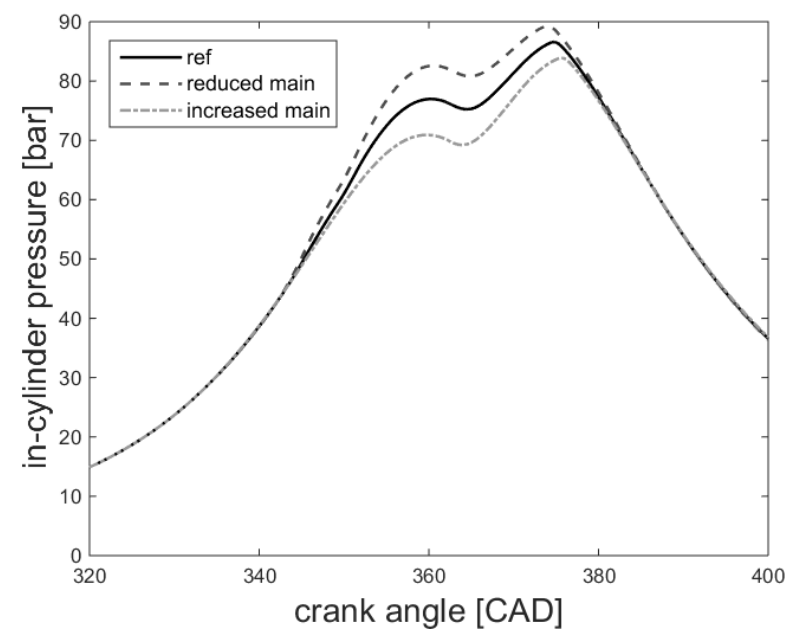

Figure 40. Injection pattern variation: in-cylinder pressure.

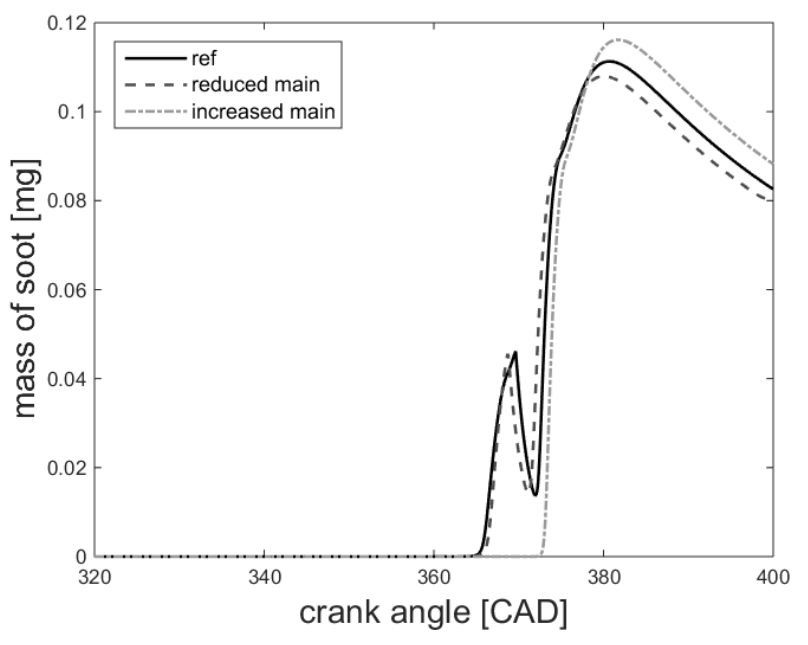

Figure 41. Injection pattern variation: mass of soot.

\section{EGR rate variation}

In this section, a variation of EGR rate is operated. Figure 42 shows the impact a variation of the EGR rate has on the in-cylinder pressure for the different operating conditions. As shown, an increasing of the EGR rate implies a slower combustion process and a reduction of the in-cylinder temperature. More in details, the presence of EGR in ambient gas, reduces the mass fraction of air, which implies an increasing of the lol [28], as shown in Figure 43; furthermore, a reduction of EGR rate, that is a reduction of inert gas within the reactive mixture, brings to higher combustion temperatures, in general, but in particular at stoichiometric conditions at which soot is oxidized, Figure 44, bringing to lower soot emissions at the end of the combustion process, Figure 45 . Simulation results agree with what observed in [38].

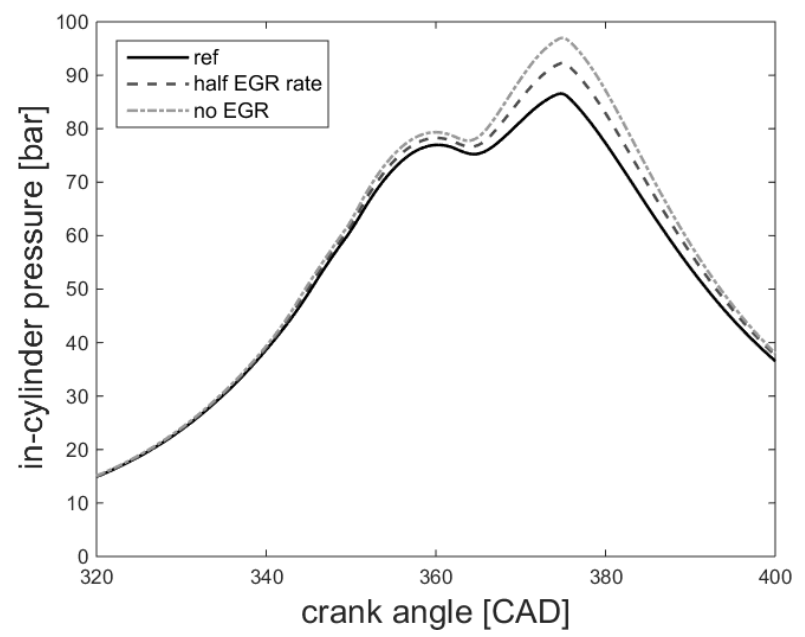

Figure 42. EGR rate variation: in-cylinder pressure. 


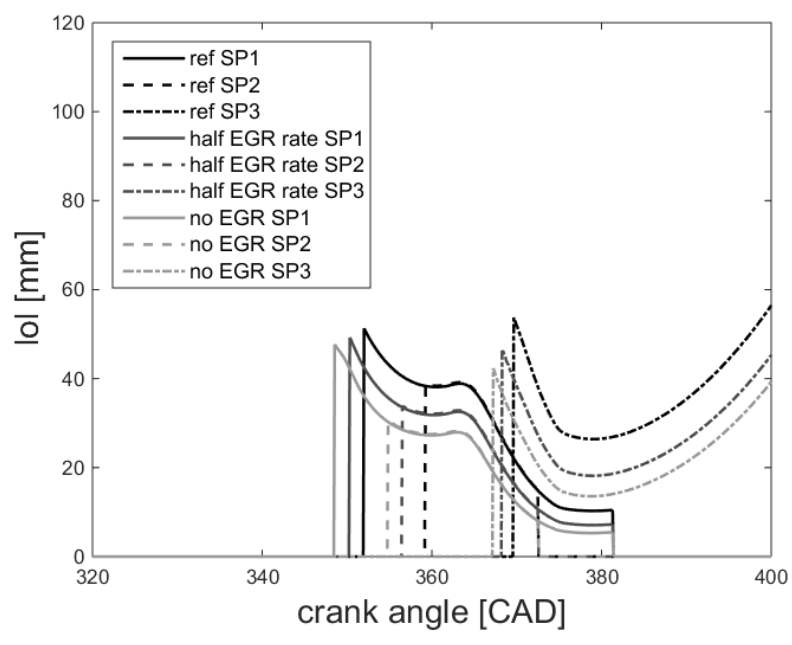

Figure 43. EGR rate variation: $l o l$ per injection.

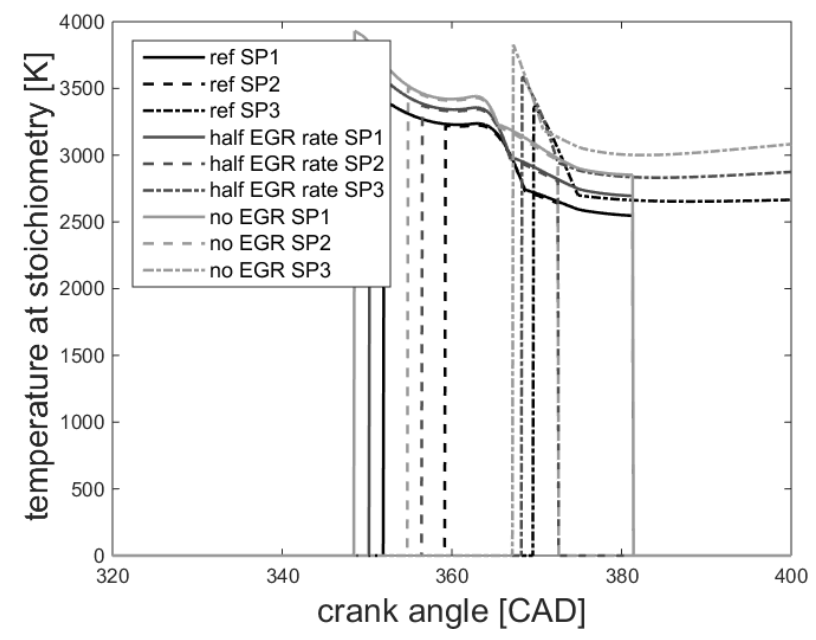

Figure 44. EGR rate variation: temperature at stoichiometry per injection.

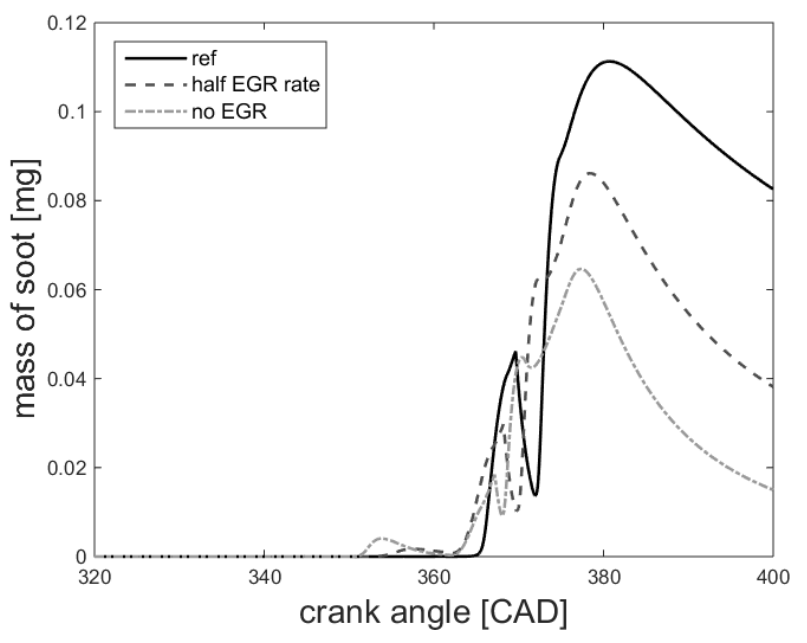

Figure 45. EGR rate variation: mass of soot.
To assess the capability of the model to deal with engine calibration optimization to reduce pollutant emissions, a sweep of EGR rate was computed. For this, the burned gas mass fraction within the cylinder at Inlet Valve Closing (IVC) was varied from $0 \%$ up to $30 \%$ by steps of $2 \%$, Figure 46 . In the figure, squares represent the simulation results ( $0 \%$ of burned gases on the RHS), while the circle represents the reference point belonging to the engine database, Figure 17. As shown, the DFM model predicts consistently the soot-NOx trade-off for a variation of the EGR rate. This is an encouraging result opening to further integration of system simulation for engine development processes.

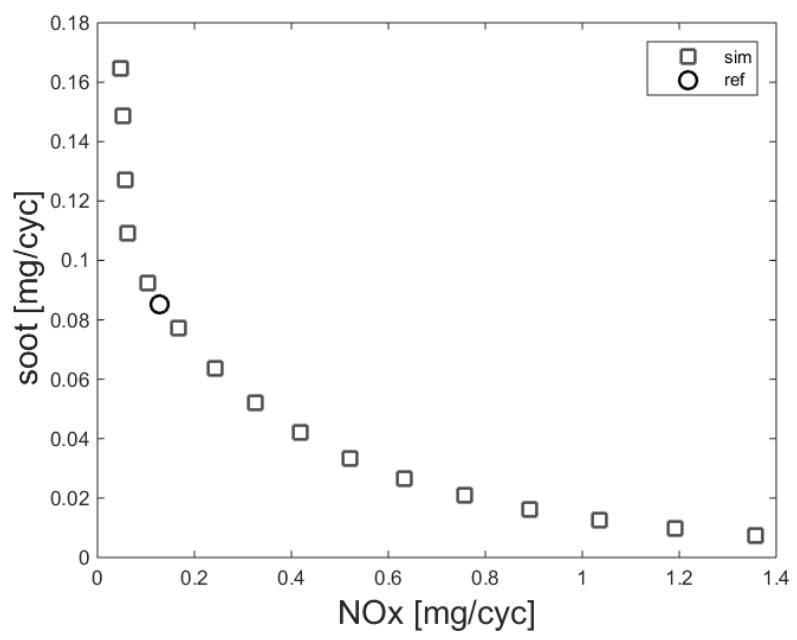

Figure 46. EGR rate variation: soot-NOx trade-off.

\section{Engine speed variation}

In this section, a variation of engine speed is operated. Figure 47 shows the impact a variation of the engine speed has on the incylinder pressure for the different operating conditions. As shown, an increasing of the engine speed implies a slower combustion process as a function of the crankshaft coordinate. In the same fashion, Figure 48 illustrates the fact that fuel injection requires a wider crankshaftangle interval to be completed, at higher engine speed. As a result, at low engine speed a larger fraction of fuel combustion takes place close to the Top Dead Center (TDC), i.e. at higher pressure and temperature, conditions that improve the soot oxidation; moreover, at low engine speed, there is more time for soot oxidation. Both those factors lead to a decreasing of soot emissions with a decreasing of the engine speed, Figure 49. This result is in agreement with what was found in [38]. 


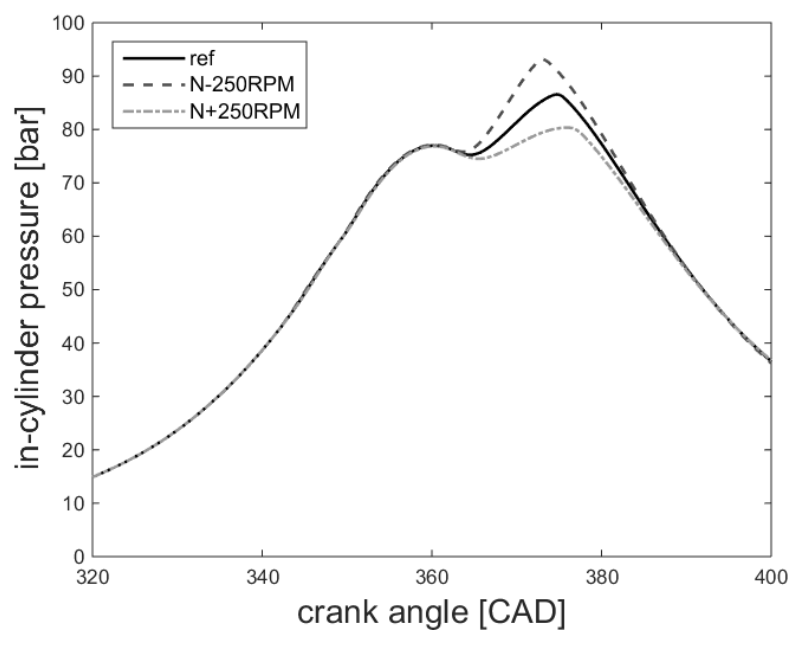

Figure 47. Engine speed: in-cylinder pressure.

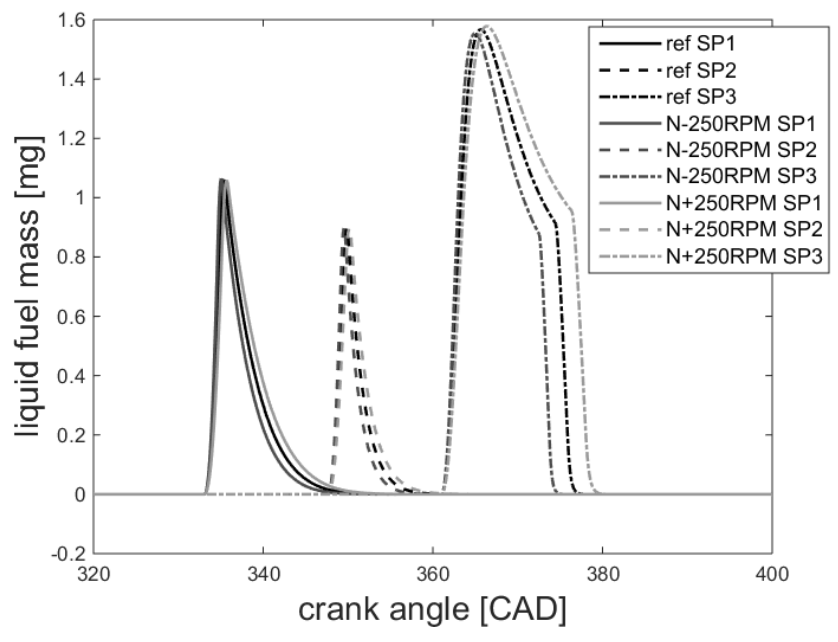

Figure 48. Engine speed: in-cylinder liquid mass of fuel per injection.

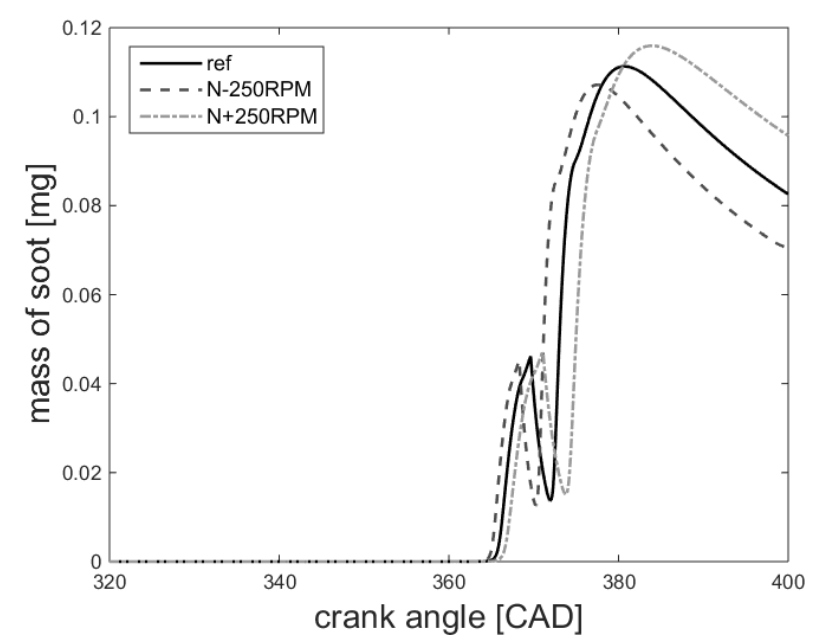

Figure 49. Engine speed: mass of soot.

Page 17 of 19

\section{Conclusions}

This paper detailed the development of a spray-based phenomenological soot-model for Diesel engine. The approach, based on the conceptual Diesel combustion model proposed by SNL, computes relevant aspects related to the spray impacting the soot formation and oxidation. In particular, variables such as liquid length penetration and ambient gas entrainment within the spray region, but also the lift-off length and the mixture equivalence ratio at lift-off length, which was found to well correlate to soot formation intensity, are resolved all along the engine cycle simulation. The used formalism makes the model suitable to manage soot formation processes under multiple-injection strategies as well. The soot model was then integrated within the DFM combustion model to simulate real engine behaviors. These developments were tested over a complete engine database representative of the whole engine operating domain, in order to assess the potential of the new model to predict soot emissions. The model proved to be able to predict with good accuracy qualitative trends in soot emissions as a function of the engine calibration for the different engine operating conditions, but also, with an acceptable accuracy, quantitative soot emissions. As a further investigation, single parameter variations from a reference engine operating point were performed numerically, to further assess the robustness of the model, but also to investigate the model response, both in terms of soot emissions and capability to describe the underlying phenomenology. For this, variations of injection pressure, injection timing, injection pattern, EGR rate and engine speed were performed. The model showed consistent behaviors in terms of phenomenology and observed soot emissions variations were in agreement with what was found in the literature.

\section{References}

1. Flynn P. and al. "An Experimental Determination of the Instantaneous Potential Radiant Heat Transfer Within an Operating Diesel Engine". SAE Technical Paper 720022, doi:10.4271/720022, 1972.

2. Boulouchos K. et al. "New Insights into the Mechanisms of InCylinder Heat Transfer in Diesel Engines". SAE Technical Paper 890573, doi:10.4271/890573, 1989.

3. Struwe F. and Foster D. "In-Cylinder Measurement of Particulate Radiant Heat Transfer in a Direct Injection Diesel Engine". SAE Technical Paper 2003-01-0072, doi:10.4271/2003-01-0072, 2003.

4. Mueller C.J. Boehman A.L., and Martin G.C. “An Experimental Investigation of the Origin of Increased NOx Emissions When Fueling a Heavy-Duty Compression-Ignition Engine with Soy Biodiesel". SAE Technical Paper 2009-01-1792, 2009.

5. Dec J. "A Conceptual Model of DI Diesel Combustion Based on LAser Sheet Imaging”. SAE Technical Paper 970873, 1997.

6. Bruneaux G. "Combustion structure of free and wall impinging diesel jets by simultaneous laser-induced fluorescence of formaldehyde, poly-aromatic hydrocarbons, and hydroxides". International Journal of Engine Research, 9: p. 249-265, 2008.

7. Aubagnac-Karkar D., Michel J.-B., Colin O., Noel L. et al. "A Sectional Soot Model for RANS Simulation of Diesel Engines". SAE Technical Paper, 2014-01-1590, 2014.

8. Fraioli V., Beatrice C. and Lazzaro M. "Soot particle size modelling in 3D simulations of diesel engine combustion". Combustion Theory and Modelling, 15(6):863-892, doi:10.1080/13647830.2011.578662, 2011.

9. Finesso R., Spessa E., Mancaruso E., Sequino L. and Vaglieco B.M. "Spray and soot formation analysis by means of a quasidimensional multizone model in a single cylinder Diesel engine 
under euro 4 operating conditions". SAE Technical Paper 201524-2416, 2015.

10. Karaky H., Mauviot G. and Tauzia X. "Semi-Empirical OD Modeling for Engine-Out Soot Emission Prediction in D.I. Diesel Engines". SAE Technical Paper, 2016-01-0562, 2016.

11. Bayer J. and Foster D. "Zero-Dimensional Soot Modeling". SAE Technical Paper, 2003-01-1070, 2003.

12. Lebas R., Fremovici M., Font G. and Le Berr F. "A Phenomenological Combustion Model Including In-Cylinder Pollutants To Support Engine Control Optimization Under Transient Conditions". SAE Technical Paper, 2011-01-1837, 2011.

13. Mauviot G., Albrecht A. and Poinsot T.J. "A New 0D Approach for Diesel Combustion Modeling Coupling Probability Density Function with Complex Chemistry". SAE Technical Paper, DOI: 10.4271/2006-01-3332, 2003.

14. Pickett L. et al. "Relationship Between Diesel Fuel Spray Vapor Penetration/Dispersion and Local Fuel Mixture Fraction". SAE Technical Paper 2011-01-0686, 2011.

15. Pickett L. and Siebers D. "Soot in Diesel fuel jets: effects of ambient temperature, ambient density, and injection pressure". Combustion and Flame, 138: p. 114-135, 2004.

16. “2nd ECN workshop 7-8 Sept. 2012". Heidelberg, Germany, http://www.sandia.gov/ecn/workshop/ECN2.php, 2012.

17. Naber J. and Siebers D. "Effects of Gas Density and Vaporization on Penetration and Dispersion of Diesel Sprays". SAE Technical Paper 960034, 1996.

18. Malbec L.-M. "Étude expérimentale des mécanismes d'entrainement d'air et de formation du mélange dans les jets Diesel, et impact sur la combustion et la formation des suies". $\mathrm{PhD}$ thesis, Université d'Orléans, 2013.

19. Idicheria C.A. and Pickett L.M. "Soot formation in Diesel combustion under high-EGR conditions". SAE Technical Paper 2005-01-3834, 2005.

20. Dulbecco A., Lafossas F.-A., Mauviot G. and Poinsot T.J. "A New 0D Diesel HCCI Combustion Model Derived from a 3D CFD Approach with Detailed Tabulated Chemistry". OGST, DOI: 10.2516/ogst/2008051, 2009.

21. Rudloff J., Dulbecco A. and Font G. "The Dual Flame Model (DFM): A Phenomenological 0D Diesel Combustion Model to Predict Pollutant Emissions". SAE Technical Paper, DOI: 10.4271/2015-24-2388, 2015.

22. Dulbecco A., Lafossas F.-A. and Poinsot T.J. "A OD Phenomenological Approach to Model Diesel HCCI Combustion with Multi-Injection Strategies Using Probability Density Functions and Detailed Tabulated Chemistry". SAE Technical Paper, DOI: 10.4271/2009-01-0678, 2009.

23. Lafossas F.-A., Marbaix M. and Menegazzi P. "Development and Application of a OD D.I. Diesel combustion model for emissions prediction". SAE Technical Paper, 2007-01-1841, 2007.

24. Lefebvre A.H. "Drop evaporation, in Atomization and sprays". Hemisphere Publishing Corporation, USA, 1989.

25. Dent J. "A Basis for the Comparison of Various Experimental Methods for Studying Spray Penetration". Transactions of the SAE, 80: p. 1881-1884, 1971.

26. Wakuri Y. et al. "Studies of the Penetration of Fuel Spray in a Diesel Engine". Bulletin of JSME, 3 (9), 1960.

27. Siebers D.L. "Scaling Liquid-Phase Fuel Penetration in Diesel Sprays Based on Mixing-Limited Vaporization. SAE Technical Paper 1999-01-0528, 1999.

28. Siebers D., Higgins B. and Pickett L. "Flame Lift-Off on DirectInjection Diesel Fuel Jets: Oxygen Concentration Effects". SAE Technical Paper 2002-01-0890, 2002.
29. Siebers D.L. "Liquid-Phase Fuel Penetration in Diesel Sprays". SAE Technical Paper 980809, 1998.

30. Verhoeven D., Vanhemelryck J-L. and Baritaud T. "Macroscopic and ignition characteristics of high-pressure sprays of single-component fuels". SAE Technical Paper, ${ }^{\circ}$ 981069, 1998.

31. Peters N. "Turbulent Combustion". Cambridge University Press, 2000.

32. Siebers D. and Higgins B. "Flame Lift-Off on Direct-Injection Diesel Sprays Under Quiescent Conditions". SAE Technical Paper 2001-01-0530, 2001.

33. Flynn P. et al. "Diesel Combustion: An Integrated View Combining Laser Diagnostics, Chemical Kinetics, and Empirical Validation". SAE Technical Paper 1999-01-0509, 1999.

34. Hiroyasu H. and Kadota T. "Models for Combustion and Formation of Nitric Oxide and Soot in Direct Injection Diesel Engines". SAE Technical Paper 760129, 1976.

35. Heywood J.B. "Internal Combustion Engine Fundamentals". McGraw-Hill, 1988.

36. Dulbecco A. "Modeling of Diesel HCCI combustion and its impact on pollutant emissions". PhD thesis, Institut National Polytechnique de Toulouse, 2010.

37. Hatzipanagiotou A., Wenzel P., Krueger C., Payri R., GarciaOliver J.M., Vera-Tudela W. and Koch T. "Soot Model Calibration Based on Laser Extinction Measurements". SAE Technical Paper, 2016-01-0590, 2016.

38. Westlund A., Ångström H.E. and Lindström M. "Validation of a Simplified Model for Combustion and Emission Formation in Diesel Engines Based on Correlations for Spray Penetration and Dispersion, Gas Entrainment into Sprays and Flame Lift-off'. SAE Technical Paper, 2010-01-1494, 2010.

39. Pang K.M., Poon H.M., Ng H.K., Gan S. and Schramm.J. "Soot Formation Modeling of n-dodecane and Diesel Sprays under Engine-Like Conditions". SAE Technical Paper, 2015-24-2468, 2015.

40. Polonowski C.J. et al. "An Experimental Investigation of LowSoot and Soot-Free Combustion Strategies in a Heavy-Duty, Single-Cylinder, Direct-Injection, Optical Diesel Engine”. SAE Technical Paper 2011-01-1812, doi:10.4271/2011-01-1812, 2011.

41. Upatnieks A. and Mueller C.J. "Investigation of the Relationship Between DI Diesel Combustion Processes and Engine- Out Soot Using an Oxygenated Fuel". SAE Technical Paper 2004-011400, doi: 10.4271/2004-01-1400, 2004.

42. Musculus M.P.B. "Effects of the In-Cylinder Environment on Diffusion Flame Lift-Off in a DI Diesel Engine". SAE Technical Paper 2003-01-0074, doi:10.4271/2003-01-0074, 2003.

\section{Contact Information}

Alessio Dulbecco, IFP Energies nouvelles, 1 \& 4 avenue de BoisPréau, 92852 Rueil-Malmaison, France.

Email: alessio.dulbecco@ifpen.fr

\section{Definitions/Abbreviations}

0D

0-Dimensional

3D

3-Dimensional

AI Auto-Ignition

Page 18 of 19 
CFD

CI

Computational Fluid Dynamics

Compression Ignition

Dual Flame Model

DI

Direct Injection

EGR

Exhaust Gas Recirculation

EOP

HRR

ICE

IFPEN

IMEP

IVC

LEM

LII

Internal Combustion Engine

IFP Energies nouvelles

Indicated Mean Effective Pressure

Intake Valve Closing

Laser Extinction Method

Laser Induced Incandescence lol

PAH

QD

RHS

SNL

SOI

TDC
Lift-off length

Polycyclic Aromatic Hydrocarbons

Quasi-Dimensional

Right Hand Side

Sandia National Laboratories

Start Of Injection

Top Dead Center

Page 19 of 19

$10 / 19 / 2016$ 